\title{
Atypical Mesenchymal Stromal Cell Responses to Topographic Modifications of Titanium Biomaterials Indicate Cytoskeletal- and Genetic Plasticity-Based Heterogeneity of Cells
}

\author{
Mohammad R. Khan $\mathbb{D}^{1},{ }^{1}$ Nicola Mordan, ${ }^{1}$ Mohamed Parkar, ${ }^{1}$ Vehid Salih, ${ }^{1,2}$ \\ Nikolaos Donos, ${ }^{1,3}$ and Peter M. Brett ${ }^{1,4}$ \\ ${ }^{1}$ Biomaterials and Tissue Engineering, UCL Eastman Dental Institute, University College London, 256 Gray's Inn Road, \\ London WC1X 8LD, UK \\ ${ }^{2}$ Faculty of Medicine \& Dentistry, University of Plymouth, Drake Circus, Plymouth PL4 8AA, UK \\ ${ }^{3}$ Institute of Dentistry, Queen Mary University of London, Turner Street, London E1 2AD, UK \\ ${ }^{4}$ University of Surrey, Guildford, Surrey GU2 7XH, UK
}

Correspondence should be addressed to Mohammad R. Khan; m.r.khan@ucl.ac.uk

Received 28 August 2018; Revised 3 May 2019; Accepted 20 May 2019; Published 1 July 2019

Academic Editor: Fermin Sanchez-Guijo

Copyright (c) 2019 Mohammad R. Khan et al. This is an open access article distributed under the Creative Commons Attribution License, which permits unrestricted use, distribution, and reproduction in any medium, provided the original work is properly cited.

\begin{abstract}
Titanium (Ti) is widely used as a biomaterial for endosseous implants due to its relatively inert surface oxide layer that enables implanted devices the ability of assembling tissue reparative components that culminate in osseointegration. Topographic modifications in the form of micro- and nanoscaled structures significantly promote osseointegration and enhance the osteogenic differentiation of adult mesenchymal stromal cells (MSCs). While the biological mechanisms central to the differential responses of tissues and cells to Ti surface modifications remain unknown, adhesion and morphological adaptation are amongst the earliest events at the cell-biomaterial interface that are highly influenced by surface topography and profoundly impact the regulation of stem cell fate determination. This study correlated the effects of Ti topographic modifications on adhesion and morphological adaptation of human MSCs with phenotypic change. The results showed that modified Ti topographies precluded the adhesion of a subset of MSCs while incurring distinct morphological constraints on adherent cells. These effects anomalously corresponded with a differential expression of stem cell pluripotency and Wnt signalling-associated markers on both modified surfaces while additionally differing between hydrophobic and hydrophilic surface modifications-though extent of osteogenic differentiation induced by both modified topographies yielded similarly significant higher levels of cellular mineralisation in contrast to polished $\mathrm{Ti}$. These results suggest that in the absence of deposited proteins and soluble factors, both modified topographies incur the selective adhesion of a subpopulation of progenitors with relatively higher cytoskeletal plasticity. While the presence of deposited proteins and soluble factors does not significantly affect adherence of cells, nanotopographic modifications enhance expression of pluripotency markers in proliferative conditions, which are conversely overridden by both modified topographies in osteogenic inductive conditions. Further deciphering the mechanisms underlying cellular selectivity and Ti topographic responsiveness will improve our understanding of stem cell heterogeneity and advance the potential of MSCs in regenerative medicine.
\end{abstract}

\section{Introduction}

Titanium (Ti) is widely used as a biomaterial for dental and orthopaedic endosseous applications due to its mechanical properties and high biocompatibility. Highly reactive in its elemental state, Ti spontaneously forms a relatively bioinert surface oxide layer that enables endosseous devices the ability of assembling tissue reparative components that culminate in osseointegration, an uninterrupted contact between the surface of an implant and adjacent bone $[1,2]$. Enhancements 
to the quantifiable parameters of osseointegration that include increased implant-bone contact, denser accrual of peri-implant bone, and a stronger mechanical interlock have been widely reported for $\mathrm{Ti}$ implants modified to a moderately rough topography by sand blasting and acid etching (SLA) [3-9]. An additional modification at the nanotopographic scale that renders the SLA surface hydrophilic due to increased surface-free energy by preventing adsorption of hydrocarbons has more recently been reported to further promote clinically graded osseointegration compared to the hydrophobic SLA in human and animal studies [10-13]. Experimental evidence implicates an earlier induction of osteogenic and angiogenic responses coupled with the inhibition of bone remodelling and inflammation as primary factors contributing to the temporal enhancement of osseointegration with modified SLA (modSLA) [14-17].

The in vitro study of cellular responses to the SLA and modSLA collectively suggests a novel promotion of osteogenic differentiation, maturation, and function [18-20]. These effects seem particularly evident for bone marrowderived mesenchymal stromal cells (MSCs) that are multipotent clonogenic cells expressing a highly specific repertoire of cell surface markers and are capable of trilineage differentiation to osteogenic, adipogenic, and chondrogenic phenotypes [21]. In addition to the potential therapeutic benefits and a proposed role in wound repair, MSCs are an important model for in vitro cell and tissue developmental studies. Our observations of MSC responses to the SLA and modSLA have correlated a relatively earlier induction of cell growth, survival, and osteogenic differentiation-related genetic markers with an enhancement in extracellular matrix elaboration and calcification, with a further correlation drawn with the concomitant downregulation of cell signalling molecules believed to confer MSCs with multipotentiality [20, 22, 23].

Furthermore, due to a highly sensitive and responsive mechano-transduction apparatus, MSC fate determination is significantly dependent on adhesion and morphological cues [24]. Experimental evidence pertaining to MSCs and osteoblasts variably reports differences in cellular attachment but consistently indicates distinct morphological differences between cells adhering to the polished and modified Ti surfaces [18, 25-28]. More recent investigations have implicated the GTPase RhoA and ROCK signalling with increased osteoblastic cell differentiation on the SLA and modSLA due to morphological constraints enacting on various cytoskeletal components [29-31]. These constraints affect the structuring of actin and myosin fibres during cell adhesion, which activates intracellular signalling related to the induction of osteogenic differentiation [32]. Importantly, however, while the cellular mechanisms correlating MSC adhesion and morphological adaptation to topographical cues of the SLA and modSLA have been defined to some extent, additional biological factors such as protein deposition and soluble molecules in the immediate microenvironment that may significantly influence surface-related effects on intracellular signalling and phenotypic maturation are yet to be known [30].

Accordingly, the present study compared adhesion and morphological adaptation of human MSCs to Ti biomaterials with different topographic modifications and correlated these differences with the expression of stemness-related pluripotency markers and osteogenic differentiation. It proposed that adhesion and morphological adaptation to modified $\mathrm{Ti}$ surfaces would differentially affect the regulation of expression of genes imparting MSCs with stem cell multipotency in conjunction with chemical cues from growth and osteogenic culture media in determining stem cell fate. In order to examine this hypothesis, adult human bone marrowderived MSCs were seeded on tissue culture polystyrene (TCP), polished (P), hydrophobic SLA and hydrophilic SLA (modSLA) surfaces in a serum-free culture medium. Cell labelling assays were used to initially estimate the number of adherent cells at 1,3 , and 24 hours postcontact and thereafter at 15 min intervals within the first hour of cell-substrate contact. Samples from the cell adhesion experiments were examined with back-scattered electron microscopy to confirm the relative number of adherent cells and then sputter coated for scanning electron microscopy to image morphological differences between MSCs on the different Ti surfaces. In addition to an osteogenic mineralisation assay, a comparison of the expression of stemness-related pluripotency genetic markers was performed with real-time polymerase chain reactions (RT-PCR) miniarrays with further four Wnt signallingassociated markers that our experience has shown to have significant surface- and microenvironment-dependent effects.

\section{Materials and Methods}

2.1. Cell Culture. Human bone marrow-derived multipotent stromal cells (MSCs) were acquired from the Institute for Regenerative Medicine, Texas A\&M Health Science Centre, College of Medicine (USA). Three donor cell lines (Caucasian; male; 20-30-year age group) were used in this study, which had been isolated from bone marrow aspirates using Ficoll density centrifugation and characterised for single cell-derived colony formations, trilineage differentiation, and expression of a repertoire of MSC-specific cell surface markers. For this study, the MSCs were cultured according to the parameters suggested by [33]. Cells were expanded in T150 culture flasks (Nunc, Denmark) at a low seeding density of 100 cells per $\mathrm{cm}^{2}$ in growth medium (GM) that comprised minimal essential medium alpha (Gibco, UK) supplemented with 10\% lot selected fetal bovine serum (Gibco, UK), 1\% antibiotics (penicillin/streptomycin; PAA Laboratories, UK), and $0.1 \%$ fungicide (amphotericin B; Gibco, UK) in humidified conditions $\left(37^{\circ} \mathrm{C}\right.$ and $\left.5 \% \mathrm{CO}_{2}\right)$. Cultures underwent two medium changes in seven days and were harvested for experimentation on attaining $80 \%$ confluence with $0.05 \% / 0.002 \%$ Trypsin/EDTA in $\mathrm{Ca}^{+2} / \mathrm{Mg}^{+2}$-free PBS (PAA Laboratories, UK). Experiments were performed with cells that had undergone a maximum of three passages.

2.2. Titanium Biomaterials. The Ti biomaterials were supplied by Institut Straumann AG (Basel, Switzerland). Three modified Ti implant surface topographies were used in this study: a polished $(\mathrm{P})$, rough hydrophobic sand blasted acid etched (SLA), and rough hydrophilic (modSLA). These topographies were fabricated on discs of $1.8 \mathrm{~cm}^{2}$ surface area (diameter $=15 \mathrm{~mm}$ ). The methods of fabricating these 
topographies as well as the physical and chemical characterisations have been outlined in $[20,27,34]$. The P and SLA discs were passivated prior to use by immersing in $10 \% v / v$ nitric acid in deionised water, air-dried, and sterilised with UV irradiation. The modSLA discs were supplied in sterile saline in glass vials. Tissue culture plastic (TCP) was used as a control surface.

2.3. CyQuant Nucleic Acid Stain Quantification. The CyQuant GR assay (Sigma-Aldrich, UK) was used to determine the number of attached MSCs at 1,3 , and $24 \mathrm{~h}$ post seeding on TCP, P, SLA, and modSLA discs. The kit consists of a fluorescent dye that exhibits enhanced fluorescence on intercalating with double-stranded nucleic acids of ruptured cells and was used according to the manufacturer's instructions. For this experiment, human MSCs $(N=2)$ were expanded as described above. Cells were detached from culture flasks and then seeded at a density of $1 \times 10^{4}$ cells per surface in $1 \mathrm{ml}$ of serum-free basal medium (alpha-MEM, Gibco, UK). Adherence of MSCs to each surface was evaluated with three replicates $(n=3)$ per cell line. At each time point, samples were gently washed twice with PBS and lysed by $\times 3$ freezethaw cycle that alternated between $-80^{\circ} \mathrm{C}$ and room temperature, during which the samples in 24-well plates (Nunc) were firmly enclosed using sealing film (Parafilm M, Sigma-Aldrich, UK). A working solution of dye was then added at $150 \mu \mathrm{l}$ per well for $10 \mathrm{~min}$ at $4^{\circ} \mathrm{C}$ in the dark. A $100 \mu \mathrm{l}$ volume of homogenate per sample was transferred to an opaque 96-well plate (Nunc) for fluorescence intensity measurement at excitation $530 \mathrm{~nm}$ and emission $590 \mathrm{~nm}$ (Fluoroscan, Tecan, Switzerland). Total cell numbers were determined by interpolating fluorescent intensities of samples from a standard curve.

2.4. Calcein-AM Cell Label Assay. The Calcein-AM cell label (Vybrant Cell Adhesion kit, Sigma-Aldrich, UK) was used to determine the number of cells adherent to the P, SLA, and modSLA surfaces at $5,15,30$, and 60 min post seeding. For this experiment, expanded MSCs from three cell lines $(N=3)$ were trypsinised from culture flasks and normalised to a density of $5 \times 10^{6}$ cells per $\mathrm{ml}$ in growth medium in $50 \mathrm{ml}$ tubes (Falcon, UK). The cell suspension was incubated with $5 \mu \mathrm{M}$ of Calcein-AM dye in serum-free alpha-MEM for $30 \mathrm{~min}$ in humidified conditions. Labelled cells were washed three times by centrifuging at $500 \times \mathrm{g}$ for $5 \mathrm{~min}$ in PBS and resuspended in serum-free alpha-MEM for a trypan bluebased viable cell count. Viable cells in serum-free alpha-MEM were seeded at a density of $3 \times 10^{4}$ cells per disc in triplicate. This higher cell density was used compared to the previous experiment to overcome any loss of detection of fluorescence due to low adherence of cells resulting from extremely short durations of contact with the Ti surfaces. At each time point, nonadherent cells were removed by gentle pipetting and samples were gently washed three times with PBS. Fluorescence intensity was measured directly at excitation $530 \mathrm{~nm}$ and emission $590 \mathrm{~nm}$ in a fluorometer (FluoroScan, UK). Cell-related fluorescence was determined by subtracting background fluorescence readings of corresponding clean surfaces and then interpolating the difference from a standard curve. Additional samples for 3 and $24 \mathrm{~h}$ contact were prepared for morphological assessments.
2.5. Electron Microscopy. Scanning electron microscopy (SEM) was conducted on a Cambridge Stereoscan S90B (Cambridge Instruments, UK). Samples from the CalceinAM-based experiment were fixed immediately after fluorescence measurements in 3\% glutaraldehyde in $0.1 \mathrm{M}$ sodium cacodylate buffer ( $\mathrm{pH}$ 7.3) (Agar Scientific, Stansted, Essex, UK) at $4^{\circ} \mathrm{C}$ overnight. Samples were later dehydrated in a graded series of alcohols (50\%, 70\%, 90\%, and twice with $100 \%)$ and critically dried in hexamethyldisilazane (TAAB Laboratories Ltd., Reading, Berkshire, UK) for $5 \mathrm{~min}$ at room temperature. Samples were imaged with back-scattered SEM, which differentiates between an inorganic bright background and opaque/dark organic cells. A manual count was performed to verify the relative difference in the number of adherent MSCs on each surface. These samples were sputter coated with gold/palladium using a Polaron E5000 Sputter Coater (Quorum Technologies Ltd., Newhaven, East Sussex, UK) and visualised with SEM.

2.6. Gene Expression of Wnt Signalling Molecules. Real-time PCR was used to examine differences in the expression of Wnt signalling molecule osteoblastogenesis-related Wnt5a, osteoblastic marker Growth Differentiation Factor type 15 (GDF15), proliferative marker MKI67, and osteogenic marker osteocalcin (bone gamma-carboxyglutamic acid-containing protein). For this experiment, MSCs isolated from three donors $(N=3)$ were experimented in three technical replicates per donor $(n=3)$. The culture expanded MSCs $(N=3, n=3)$ were seeded at a density of $3 \times 10^{4}$ cells on TCP, P, SLA, and modSLA in growth medium (GM) and osteogenic medium (OM) for $24 \mathrm{~h}$. Samples were washed twice with PBS and lysed in situ with buffer RLT for RNA extraction with the RNeasy Mini kit (Qiagen, USA) according to the manufacturer's instructions. Total RNA was eluted with $40 \mu \mathrm{l}$ of RNAse-free water per column and nucleic acid integrity quantified by spectrophotometry (Tecan NanoDrop, Switzerland) at excitation $260 \mathrm{~nm}$ and emission $280 \mathrm{~nm}$. Then, $400 \mathrm{ng}$ of RNA per sample was converted to $100 \mu \mathrm{l}$ cDNA by first-strand synthesis reactions with the High-Capacity Reverse Transcription Kit (Applied Biosystems, USA) according to the manufacturer's instructions. Real-time PCR reactions were performed in $25 \mu \mathrm{l}$ volume reactions with $2.5 \mu \mathrm{l}$ (10 ng of RNA equivalent) of cDNA per reaction in a 7300 Real-Time PCR Thermocycler (Applied Biosystems, USA). The probes used were Hs00998537_m1 for Wnt5a; Hs00171132_m1 for GDF15; Hs01032439_m1 for MKI67; and Hs01587814_g1 for OC/ BGLAP (all from Applied Biosystems, USA). The Ct values of markers were normalised to the GAPDH housekeeping gene and calibrated to $\Delta \mathrm{Ct}$ values of cells in suspension (at time zero) to obtain relative fold value of expression.

2.7. Gene Expression of MSC Stemness Molecules. Changes in the expression of stem cell multipotency genes were evaluated with the Taqman Real-Time PCR Stem Cell Pluripotency Microfluidic Arrays (Applied Biosystems; catalogue number 4385344). These are 384 -well plates ( 8 rows, 48 columns) that contain four groups of 96 genes that represent different categories related to stem cell biology. These are (i) expression in undifferentiated cells, (ii) maintenance of 
pluripotency, (iii) correlation to stemness, and (iv) differentiation markers, in addition to endogenous controls. For this experiment, MSCs were seeded at a density of $3 \times 10^{4}$ cells on P, SLA, and modSLA in growth medium (GM) as well as osteogenic inductive medium (OM) for $24 \mathrm{~h}$. Samples were washed twice with PBS and lysed in situ with buffer RLT for RNA extraction with the RNeasy Mini kit (Qiagen, UK) according to the manufacturer's instructions. Total RNA was eluted with $40 \mu \mathrm{l}$ of RNAse-free water per column and nucleic acid integrity quantified by spectrophotometry (Tecan NanoDrop, Switzerland) at excitation 260 $\mathrm{nm}$ and emission $280 \mathrm{~nm}$. Then, $400 \mathrm{ng}$ of RNA per sample was converted to $100 \mu \mathrm{l} \mathrm{cDNA}$ by first-strand synthesis reactions with the High-Capacity Reverse Transcription Kit (Applied Biosystems, USA) according to the manufacturer's instructions. The arrays were run in an Applied Biosystems 9700 Real-Time PCR thermocycler at the University College London Institute of Child Health (London, UK). Fold values of changes in gene expression were evaluated with the $2^{-\Delta \Delta \mathrm{Ct}}$ formula. $18 \mathrm{~S}$ ribosomal RNA was used as the internal control to obtain delta Ct values. Delta $\mathrm{Ct}$ values of MSCs in suspension prior to plating cells on the surfaces were processed at the start of the experiment and used as a calibrator to obtain mean fold values of expression, which were plotted in a heatmap using the " $R$ " software for statistical computing (http://www.r-project.org/). Euclidean distance was used to cluster similarly expressed genes into groups.

2.8. Osteogenic Differentiation. Osteogenic differentiation was performed by culturing MSCs in 24-well plates for 7 days with osteogenic inductive medium (OM), comprising Dulbecco's modified Eagle's medium low glucose (Gibco) supplemented with $10 \%$ lot selected fetal calf serum (Gibco, UK), 1\% antibiotics and $0.1 \%$ fungicide (Gibco, UK), $10 \mathrm{nM}$ dexamethasone (water soluble; Sigma-Aldrich, UK), $10 \mathrm{mM} \beta$-glycerophosphate (Fisher Scientific, UK), and $50 \mu \mathrm{M}$ ascorbate-2phosphate (Fluka, UK). Samples were washed twice with PBS and fixed in 10\% formalin for 10-15 min before being stained with a $2 \%$ Alizarin Red S (Sigma-Aldrich, UK) solution in deionised water ( $\mathrm{pH}$ 4.1-4.3) for $10 \mathrm{~min}$. Samples were washed $4 \mathrm{x}$ with deionised water and air dried. Calcium-bound dye was eluted with $0.5 \mathrm{ml}$ of $10 \%(w / v)$ cetylpyridinium chloride in $10 \mathrm{mM}$ sodium phosphate buffer, $\mathrm{pH} 7.2$ (all Sigma-Aldrich, UK). Spectrophotometric absorbance of elutant was measured at $562 \mathrm{~nm}$ (Tecan, Switzerland).

2.9. Statistics. The cell-based assays were performed with primary human MSCs from three different donors $(N=3)$. Each donor was tested in three experimental replications $(n=3)$. Data was analysed with GraphPad Prism (GraphPad Inc., USA) using the ANOVA statistical test. The miniarray data was collated in " $R$ " with Euclidean algorithm used to determine similarities in gene expression patterns.

\section{Results}

3.1. MSC Adhesion to Different Ti Surfaces. Cell adhesion is the earliest event in cell-substrate interactions. It was hypothesised that the topographies of the polished, SLA, and modSLA Ti surfaces would differentially affect the adhesion of MSCs to these substrates. The results of the cellsubstrate adhesion analysis performed using CyQuant GR nucleic acid staining of human MSCs in serum-free conditions are shown in Figure 1(a). Near-maximum MSC attachment to each of the four experimental surfaces had occurred by $1 \mathrm{~h}$ with detectable incremental increases taking place only on the TCP by 3 and $24 \mathrm{~h}$. The polished Ti had a significantly higher number of adherent cells than SLA and modSLA $(p<0.001)$ at all time points. Between the rough surfaces, the hydrophobic SLA had a significantly higher number of adherent cells than the hydrophilic modSLA $(p<0.001)$ at $1 \mathrm{~h}$ and $24 \mathrm{~h}$. Hence, using TCP as a control substrate for in vitro MSC culture and adhesion, differences between the number of cells adhering to the P, SLA, and modSLA surfaces were observed with a higher number of MSCs adherent to the P surface compared to both modified surfaces at 1,3 , and $24 \mathrm{~h}$.

It was then decided to delineate differences in the earliest of time points hypothesising that contact durations of less than $1 \mathrm{~h}$ would further delineate the effects of substrates on cellular adhesion between different surfaces. This second analysis of human MSC adhesion in serum-free conditions was performed with a fluorescent cytoplasmic dye Calcein$\mathrm{AM}$ and demonstrated a significantly higher number of cells adherent to the polished Ti compared to both rough surfaces $(p<0.01)$ at all four time points within the initial $1 \mathrm{~h}$ of contact. These results are shown in Figure 1(b).

To confirm the outcome of the Calcein-AM-based cell adhesion experiment, samples were visualised with backscattered scanning electron microscopy (EM). These results are shown in Figure 1(c). A manual count of cells in the electron micrographs indicated quantitative differences with a higher number of adherent cells on the polished Ti surface compared to the rough surfaces at all points. An automated imaging software count of cells could not be performed due to an inability of software (ImageJ; https://imagej.nih.gov/ij/) to decipher cells from the topographical features of the rough surfaces.

3.2. MSC Morphology on Different Ti Surfaces. Electron microscopy of sputter coated samples was then used to image the morphology of MSCs adherent to the different Ti surfaces at different time points. The morphology of cells after adhering to the Ti surfaces following different durations of contact is shown in Figures 2-4 for the polished, hydrophobic SLA, and hydrophilic modSLA, respectively. The MSCs appeared rounded with a prominent centrally located nucleus and concentrically distributed cytoplasm at 5-30 min post contact that continued to spread over the P surface by $1 \mathrm{~h}$. By 3 to $24 \mathrm{~h}$, cells seemed to have stretched over a large area of the substrate with a flattened morphology and without a prominent nucleus observable. This sequence of cellular spreading and morphological adaptation to the $\mathrm{P}$ surface is shown in Figure 2. Conversely, MSCs appeared to have a constrained morphology on both modified rough Ti surfaces. Adherent MSCs appeared predominantly rounded for the initial hour of contact with few cytoplasmic extensions emanating into the crevices of the rough topographies. MSCs progressed to 


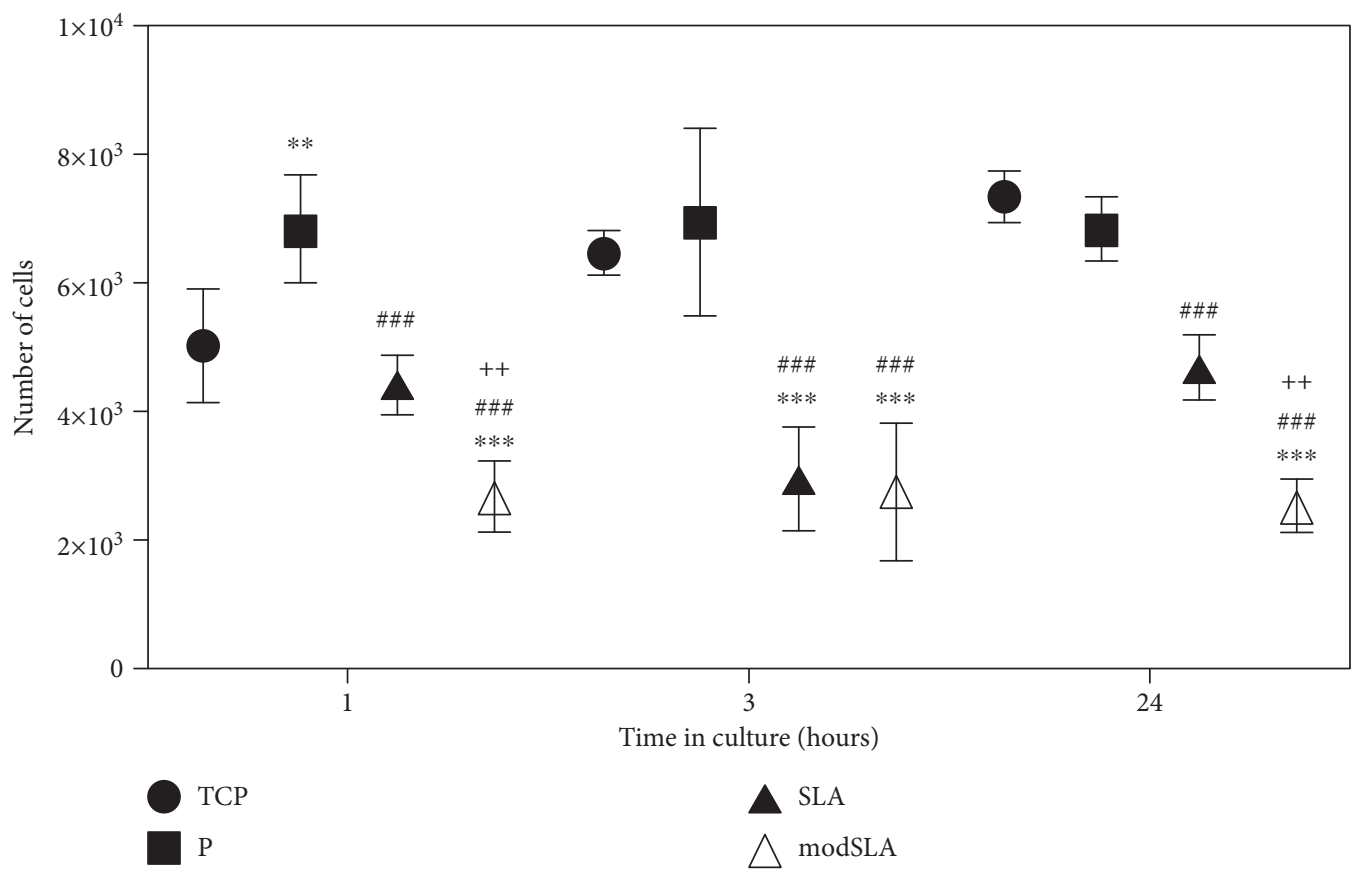

(a)

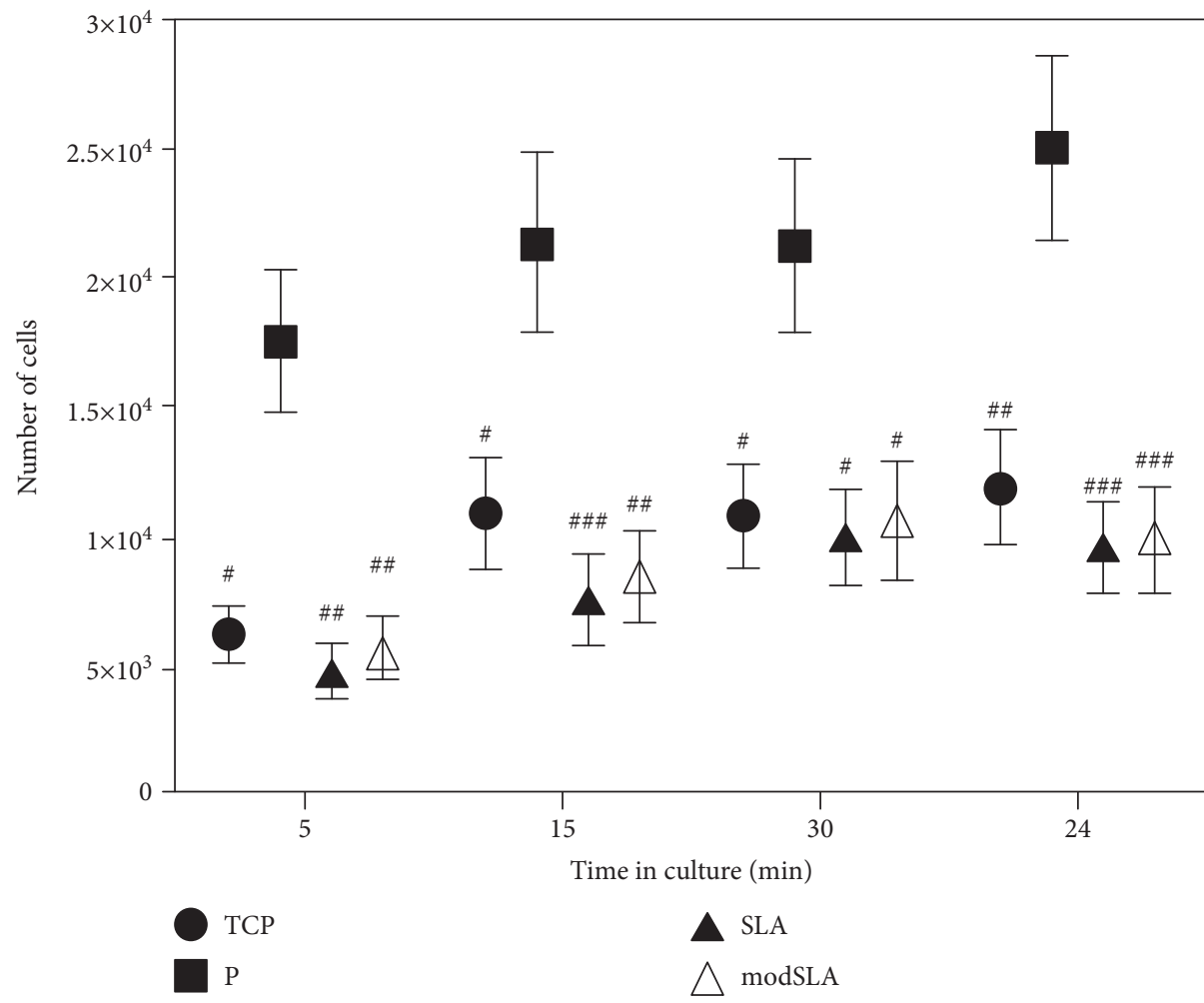

(b)

FIgURe 1: Continued. 


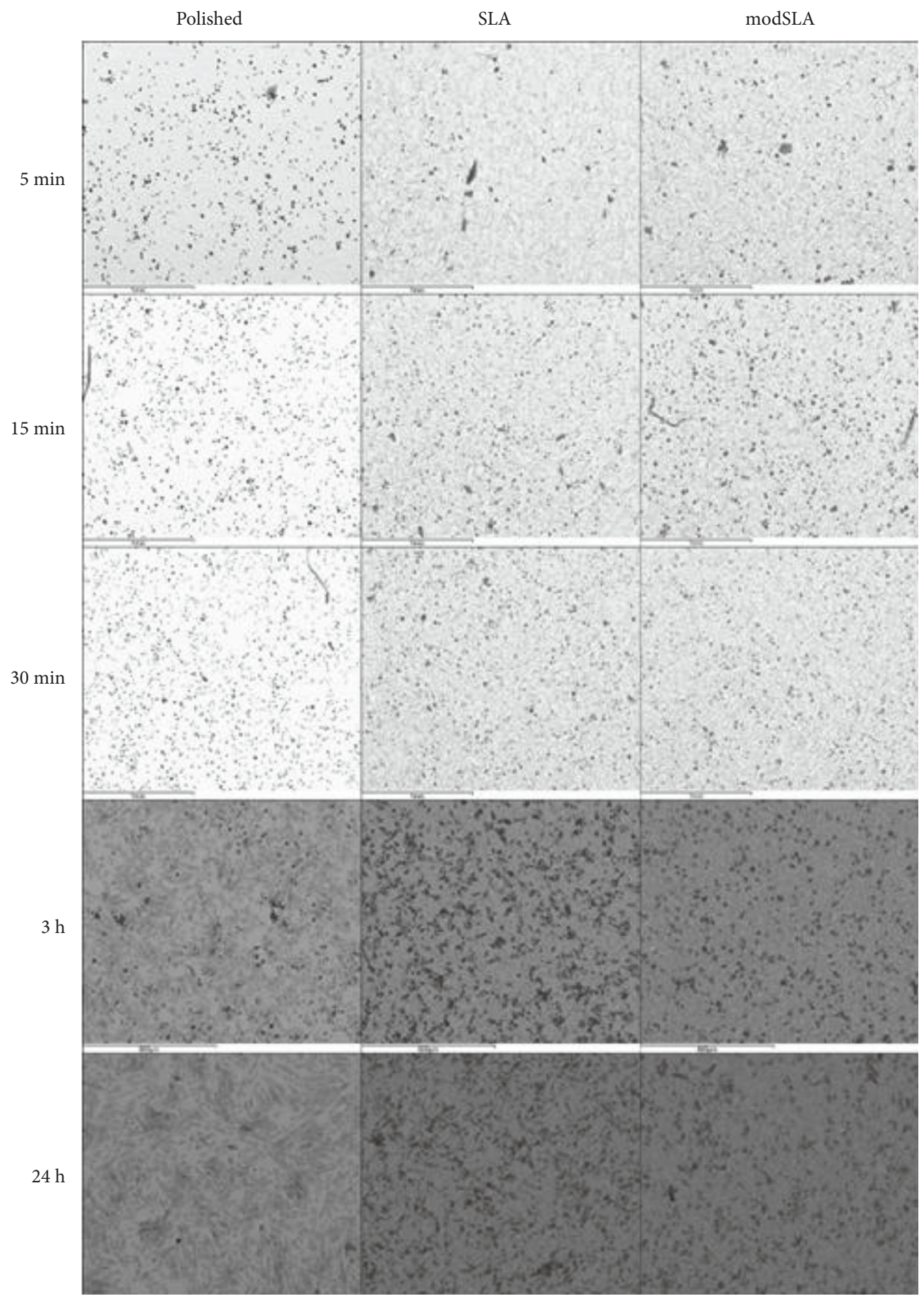

(c)

Figure 1: (a) Assessment of cell adhesion at 1, 3, and $24 \mathrm{~h}$ post contact demonstrated adherence at near-maximal numbers to each of the test surfaces by $1 \mathrm{~h}$. Cell numbers increased slightly on tissue culture plastic but remained unchanged on the Ti surfaces. There was a significantly lesser number of cells on the rough compared to polished Ti surfaces. Shown are mean $\pm \mathrm{SD}, N=$ donors $=2, n=$ replicates $=3$. ${ }^{*} p<0.05$,

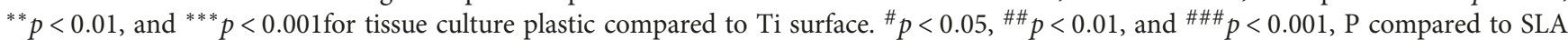
or modSLA Ti surfaces. ${ }^{+} p<0.05,{ }^{++} p<0.01$, and ${ }^{+++} p<0.001$, SLA compared to modSLA Ti surfaces. (b) Assessment of MSC adhesion within the first hour of cell-substrate contact. The Calcein-AM cytoplasmic fluorescence labelling indicated a higher number of cells adherent to the polished Ti compared with TCP and both modified rough Ti surfaces. Shown are mean $\pm \mathrm{SD}, N=3, n=3$. ${ }^{\#} p<0.05$, $\# \# p<0.01$, and \#\#\# $p<0.001$ for polished Ti compared to any surface. (c) Back-scattered scanning electron micrographs of Calceinlabelled samples from one MSC donor. Images of samples from the attachment assay confirmed the presence of a higher number of MSCs adherent to P compared to the modified rough Ti surfaces. Scale bar $=600 \mu \mathrm{m}$. 


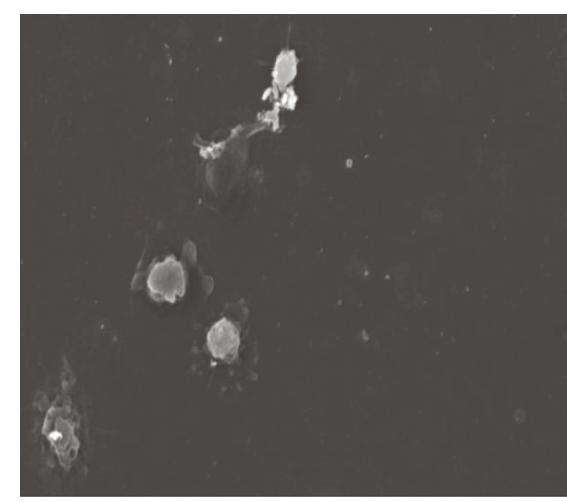

$60 \mu \mathrm{m}$

(a)

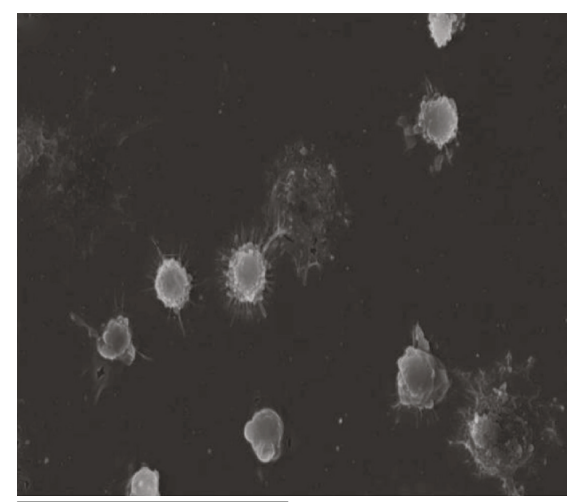

$60 \mu \mathrm{m}$

(c)

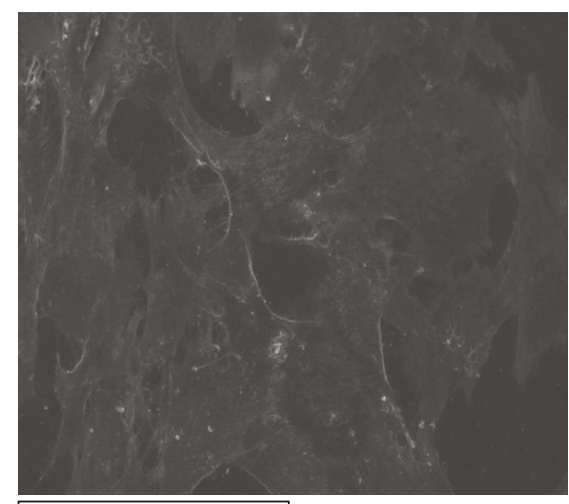

$100 \mu \mathrm{m}$

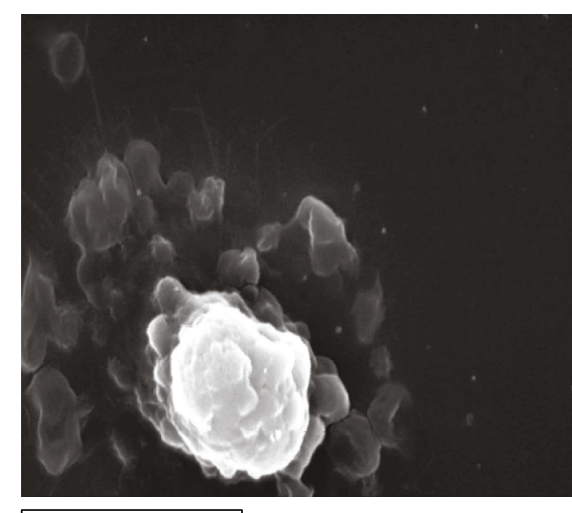

$10 \mu \mathrm{m}$

(b)

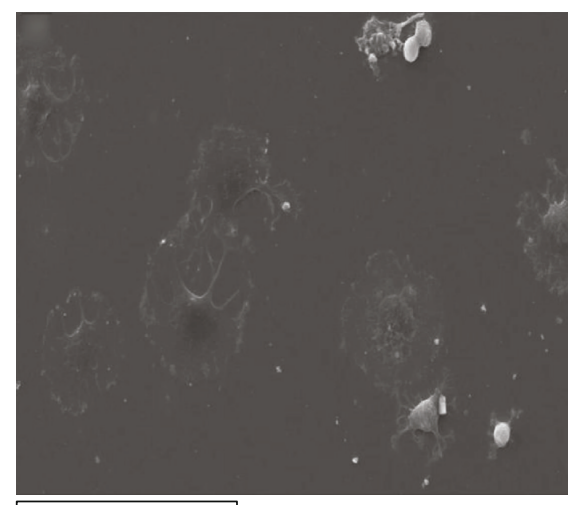

$100 \mu \mathrm{m}$

(d)

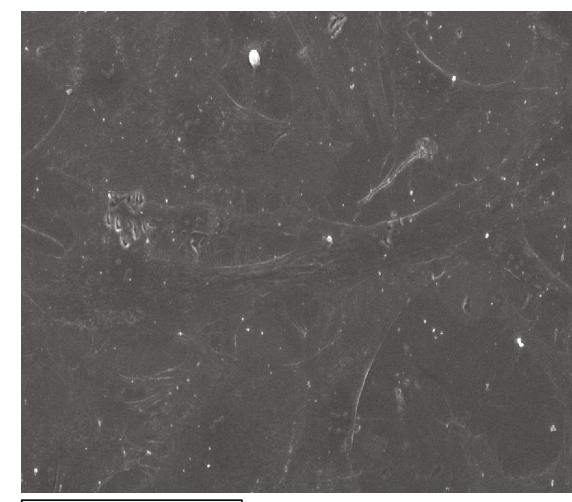

$100 \mu \mathrm{m}$

(e)

(f)

Figure 2: Morphological adaptation of MSCs on polished Ti. (a) Cells with a prominent nucleus and circumferentially spread cell membrane at 5 min post seeding. At (b) $15 \mathrm{~min}$ and (c) $30 \mathrm{~min}$, cellular spreading had increased with some cells appearing comparatively rounded by this time. (d) By $1 \mathrm{~h}$, most cells displayed a uniform circumferential spread over the surface. By (e) $3 \mathrm{~h}$ and (f) $24 \mathrm{~h}$, cells had adapted an irregular and stretched polygonal morphology.

exhibit an irregular "stellate" or star-shaped form at $3 \mathrm{~h}$ that did not change noticeably by $24 \mathrm{~h}$ on both rough surfaces. The sequence of morphological changes occurring on the SLA and modSLA is shown in Figures 3 and 4, respectively.

3.3. Gene Expression of Wnt Signalling-Related Markers. The Wnt signalling pathway is associated with several cellular processes including survival, proliferation, and differentiation. The surface- and medium-dependent effects on the expression of Wnt signalling-associated molecules Wnt5a, GDF15, MKI67, and BGLAP/OC were evaluated in MSCs cultured in proliferative growth medium and osteogenic osteoinductive medium on P, SLA, and modSLA Ti surfaces. The results of this analysis are shown in Figure 5. Wnt5a, a marker associated with the promotion of osteogenic differentiation, was expressed several folds higher by MSCs in growth medium than in osteogenic medium though differences between the different surfaces were negligible. GDF-15, a 


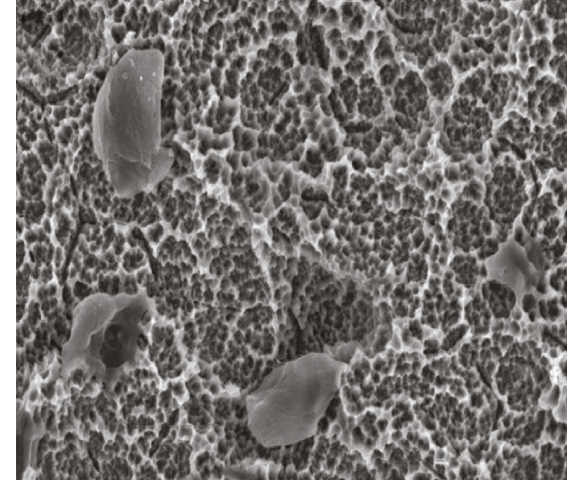

$60 \mu \mathrm{m}$

(a)

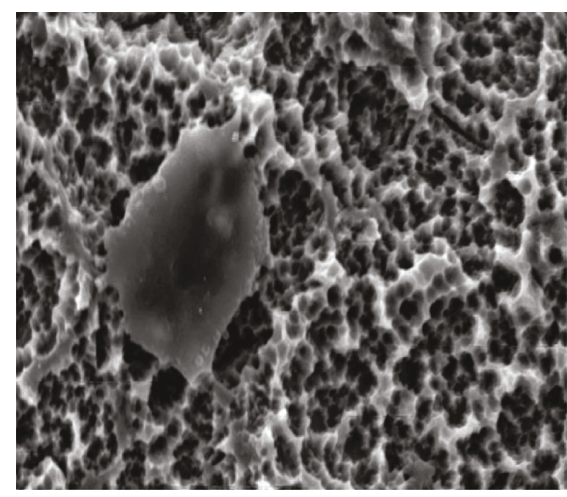

$30 \mu \mathrm{m}$

(c)

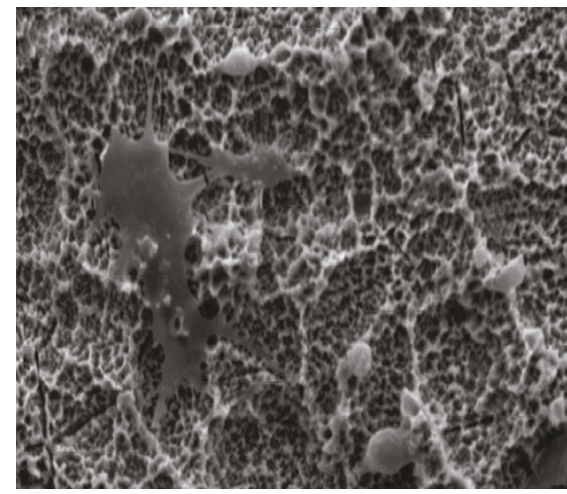

$60 \mu \mathrm{m}$

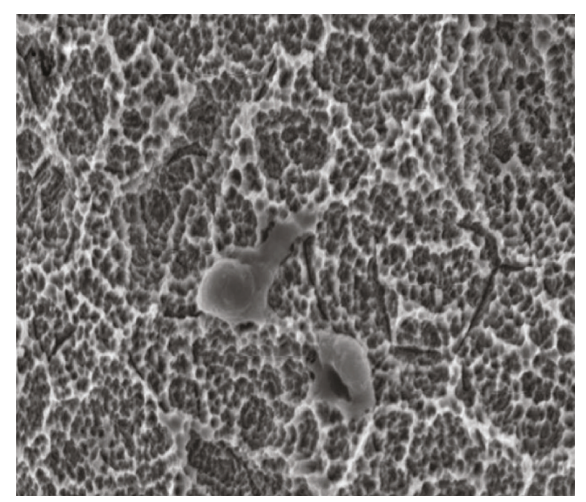

$60 \mu \mathrm{m}$

(b)

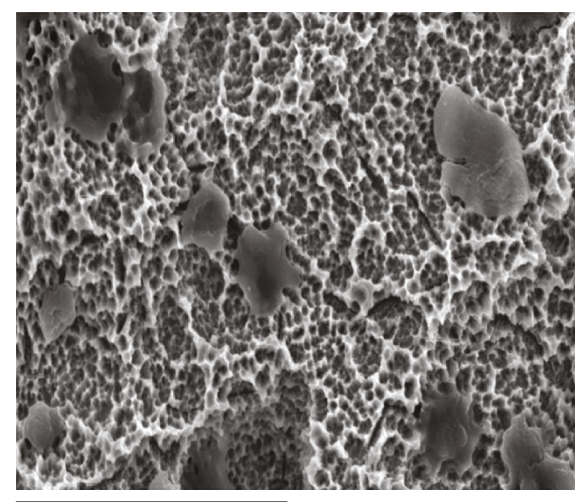

$60 \mu \mathrm{m}$

(d)

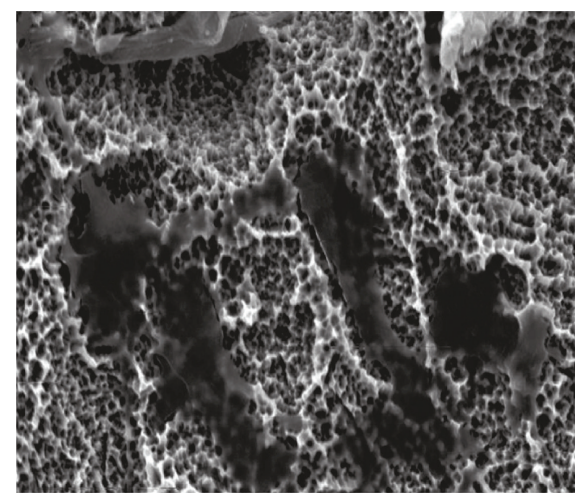

$60 \mu \mathrm{m}$

(e)

(f)

FIgURe 3: Morphological adaptation in MSCs on the SLA Ti surface. (a) At 5 min, cells appear round with membranous extensions emanating across the rough topography. At (b) $15 \mathrm{~min}$ and (c) $30 \mathrm{~min}$, cells appear constrained. At (d) $1 \mathrm{~h}$, cells displayed a slight shift from their previous circular form. At (e) $3 \mathrm{~h}$, cells had adapted a stretched asymmetric morphology that progressed till (f) $24 \mathrm{~h}$.

marker associated with the promotion of cell proliferation, was expressed at higher levels in growth medium than in osteogenic medium, with both modified topographies SLA and modSLA inducing higher expression than TCP and P in proliferative GM. The expression of proliferation marker MKI67 was markedly reduced in osteogenic than growth medium with a higher expression on TCP than Ti surfaces. Osteocalcin, a calcium and hydroxyapatite binding protein, was expressed at similar levels in both types of media with relatively increased expression on Ti surfaces. Hence, Wnt signalling-related gene expression differed in MSCs cultured in the two different medium conditions, which influenced surface-dependent effects on cells.

3.4. Gene Expression of Pluripotency Stem Cell Markers. The MSC transcriptome imparts cells with stemness characteristics. Therefore, this study evaluated the expression of stemness genes in MSCs cultured in proliferative and 


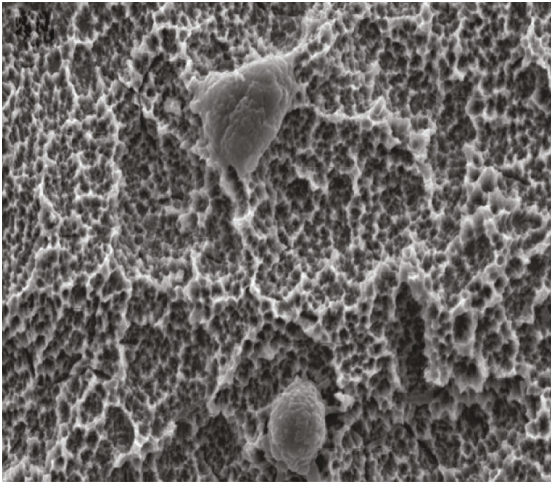

$60 \mu \mathrm{m}$

(a)

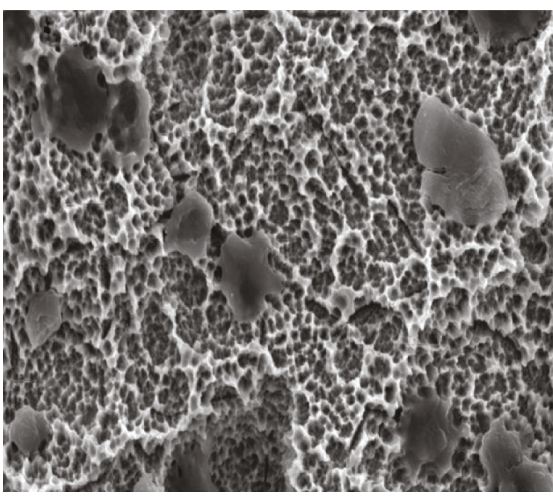

$60 \mu \mathrm{m}$

(c)

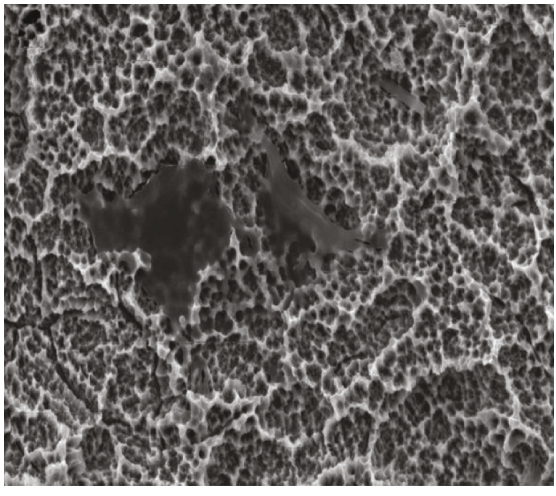

$60 \mu \mathrm{m}$

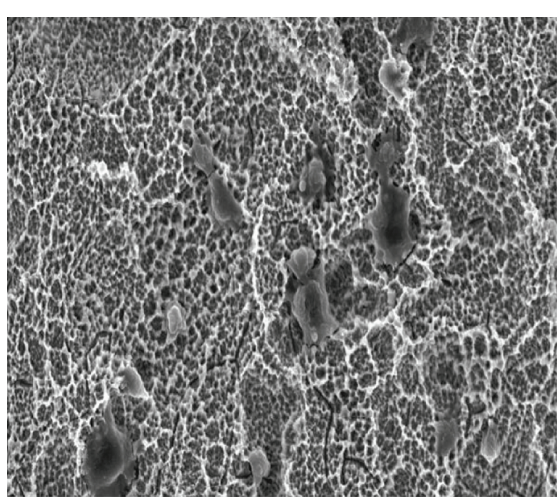

$100 \mu \mathrm{m}$

(b)

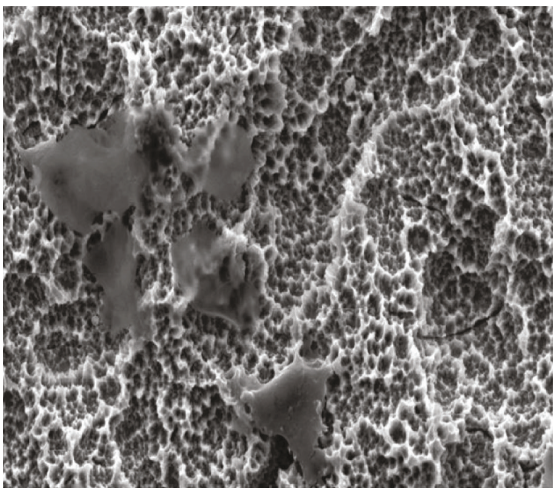

$60 \mu \mathrm{m}$

(d)

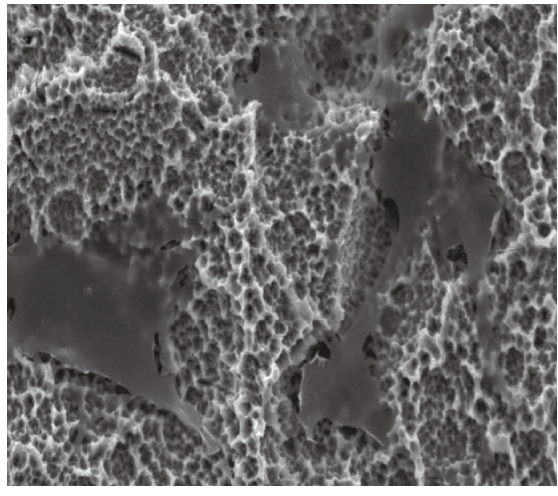

$60 \mu \mathrm{m}$

(f)

FIgURe 4: Morphological adaptation of MSCs on the modSLA Ti surface. MSCs exhibited similar morphological adaptations as when seeded on the SLA. (a-c) MSCs appeared very rounded at 5, 15, and 30 min post seeding. (d) MSCs displayed extensions emanating across the surface by $60 \mathrm{~min}$ and had (e) begun exhibiting a stretched asymmetric form by $3 \mathrm{~h}$ that continually progressed till $24 \mathrm{~h}$ (f).

osteoinductive conditions to assess the effects of surface and culture medium on MSC fate determination. The three different donor-typed MSC populations used in this study displayed high variability in the expression of pluripotency markers. To circumvent patient-specific differences, cumulative fold values of genetic marker expression were determined by adding together the fold values obtained for each donor-typed MSC population. The results of this analysis are presented in a heatmap in Figure 6 with unexpressed genetic markers listed in Table 1 and cumulative fold values of expressed markers in Table 2.

The MSCs displayed medium- and surface-dependent trends in the expression of pluripotency markers. The three donor-specific MSCs similarly lacked expression of genetic markers listed in Table 1. These markers represent embryonic or extraembryonic cellular states. The cumulative fold values of gene expression appeared variably higher in MSCs cultured on the different Ti surfaces in osteogenic inductive 

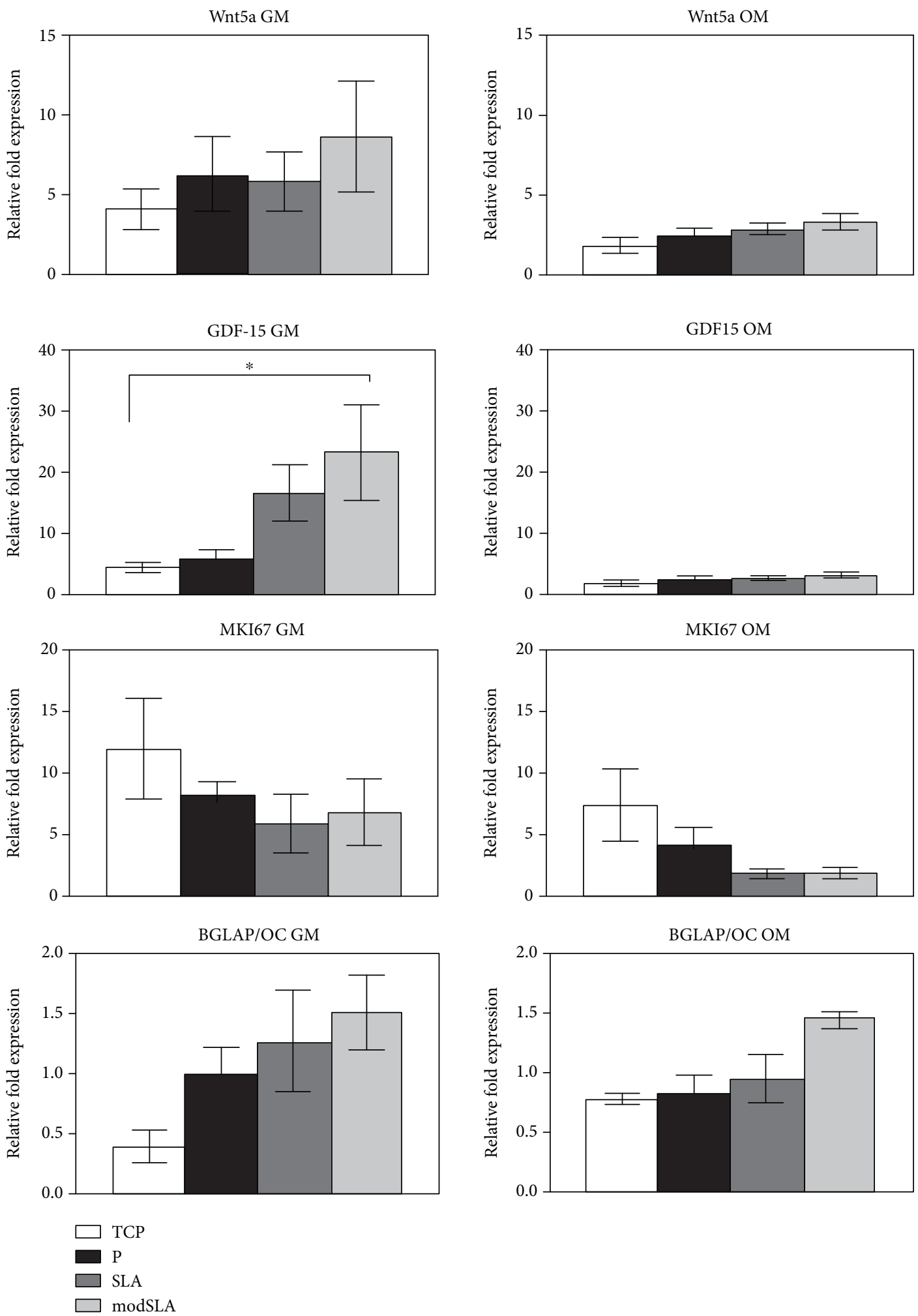

FIGURE 5: Assessment of Wnt signalling-associated genes with RT-PCR after 24 h. The Wnt molecules GDF-15 and Wnt5a were expressed by cells at higher levels in growth medium (GM) than in osteogenic medium (OM). Both molecules displayed a consistent trend of high expression on modSLA and SLA than P and TCP. Expression of proliferation marker MKI67 was markedly reduced by OM. It was expressed the highest on TCP than Ti surfaces in both medium types with rough surfaces further reducing expression in OM. OC was similar in both types of medium and displayed a trend of higher expression on modSLA. Shown are mean $+1 S D ; N=3, n=3 .{ }^{*} p<0.05$. 

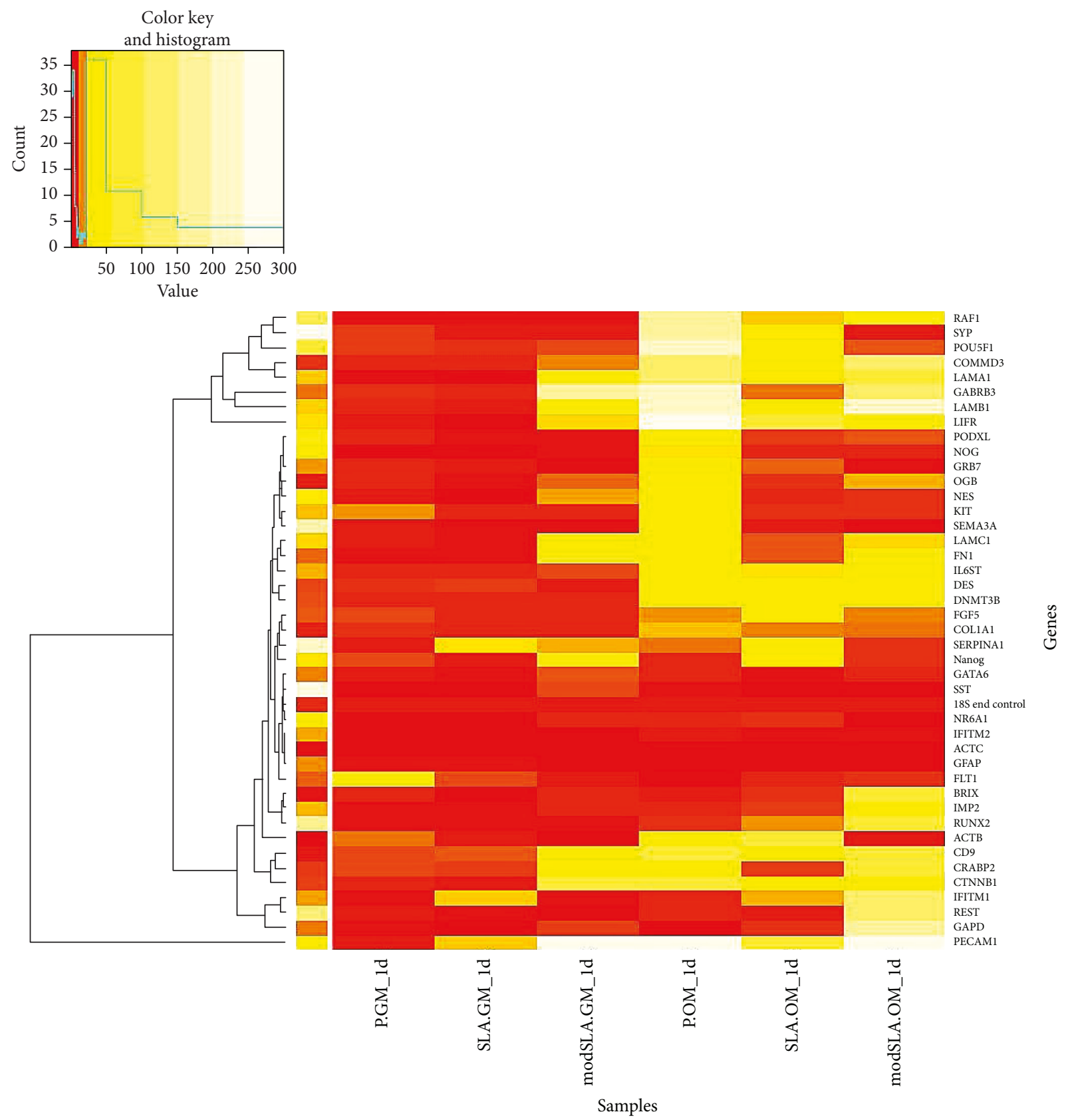

Figure 6: Analysis of pluripotency gene expression arrays in MSCs after $24 \mathrm{~h}$. A heatmap of cumulative values of fold expression represented by the minimum $(\mathrm{red}=0$ ) to the maximum (white $=300$ ). Cumulative values; $N=3, n=1$.

medium compared to proliferative growth medium. The inference was that growth medium upregulated the "expression in undifferentiated cells/maintenance of pluripotency" and "correlation to stemness" related markers in MSCs on the modSLA along with differentiation markers compared to SLA and polished Ti. Conversely, osteogenic differentiation medium variably affected the expression of all three categories of pluripotency markers in addition to the endogenous controls in MSCs cultured on the different $\mathrm{Ti}$ surfaces. A variable downregulation in "correlation to stemness" and "differentiation" marker expression was observable in MSCs on both modified topographies compared to polished.
Table 2 indicates different gene transcription profiles for MSCs cultured on the SLA and modSLA Ti surfaces with the latter significantly increasing the expression of genes key to pluripotency, stemness, and differentiation in growth medium. These differences between MSCs on SLA and modSLA are largely omitted in osteogenic inductive medium with a higher trend of expression occurring on polished. Briefly, it is suggested that MSCs upregulate the expression of pluripotency markers on modSLA in proliferation inductive growth medium while osteogenic differentiation inductive medium reduces expression of pluripotency markers on both rough surfaces compared to polished $\mathrm{Ti}$. 
TABLE 1: List of genetic markers not expressed in MSCs.

\begin{tabular}{|c|c|c|c|}
\hline Gene symbol & Category & Gene symbol & Category \\
\hline EEF1A1 & Control & GCM1 & Differentiation \\
\hline TDGF1 & Expression in undifferentiated cells & FOXA2 & Differentiation \\
\hline GDF3 & Expression in undifferentiated cells & GATA4 & Differentiation \\
\hline SOX 2 & Maintenance of pluripotency & GCG & Differentiation \\
\hline EBAF & Correlation to stemness & HBB & Differentiation \\
\hline FGF4 & Correlation to stemness & HBZ & Differentiation \\
\hline FOXD3 & Correlation to stemness & HLXB9 & Differentiation \\
\hline GAL & Correlation to stemness & IAPP & Differentiation \\
\hline GBX2 & Correlation to stemness & INS & Differentiation \\
\hline LEFTB & Correlation to stemness & IPF1 & Differentiation \\
\hline LIN28 & Correlation to stemness & ISL1 & Differentiation \\
\hline NODAL & Correlation to stemness & KRT1 & Differentiation \\
\hline NR5A2 & Correlation to stemness & MYF5 & Differentiation \\
\hline PTEN & Correlation to stemness & MYOD1 & Differentiation \\
\hline SFRP2 & Correlation to stemness & NEUROD1 & Differentiation \\
\hline TERT & Correlation to stemness & NPPA & Differentiation \\
\hline TFCP2L1 & Correlation to stemness & OLIG2 & Differentiation \\
\hline UTF1- & Correlation to stemness & PAX4 & Differentiation \\
\hline Xist & Correlation to stemness & PAX6 & Differentiation \\
\hline ZFP42 & Correlation to stemness & PTF1A & Differentiation \\
\hline AFP & Differentiation & SOX17 & Differentiation \\
\hline $\mathrm{CD} 34$ & Differentiation & SYCP3 & Differentiation \\
\hline CDH5 & Differentiation & $\mathrm{T}-$ & Differentiation \\
\hline $\mathrm{CDX} 2$ & Differentiation & TAT & Differentiation \\
\hline COL2A1 & Differentiation & $\mathrm{TH}$ & Differentiation \\
\hline DDX4 & Differentiation & WT1 & Differentiation \\
\hline EOMES & Differentiation & & \\
\hline
\end{tabular}

3.5. Osteogenic Mineralisation of MSCs on Different Surfaces. The results of this analysis are shown in Figure 7. Alizarin Red S stain retention was significantly higher for cells cultured on the modSLA surface $(p<0.001)$ compared to the other surfaces. The SLA cultured cells retained significantly more stain than polished $\mathrm{Ti}$ while the least stain was present on TCP.

\section{Discussion}

The present study has shown that in serum-free conditions, which negate the effects of deposited proteins and soluble factors, MSCs interact with $\mathrm{Ti}$ biomaterials to adhere remarkably early within very short contact durations and spread over a cross section of the substrate. The SLA and modSLA topographic modifications affect cellular adhesion and morphological adaptation causing a lesser number of cells to adhere. These adherent cells initially exhibit a highly spherical morphology while later adapting a stellate form. Conversely, MSCs adhere in larger numbers to polished $\mathrm{Ti}$ and exhibit an evenly concentric pattern of cellular spread while later adapting a stretched form. Gene expression analyses indicate a complex pattern of surface- and medium-dependent effects with Wnt signalling-associated
Wnt5a, GDF15, MKI67, and BGLAP/OC expressed at higher levels in growth than osteoinductive medium after 24 hours of contact. The pluripotency miniarrays revealed increased stem cell-related gene expression in MSCs cultured in proliferative growth conditions on the hydrophilic modSLA compared to SLA and polished $\mathrm{Ti}$, which contrasts with decreased gene expression in osteoinductive medium in MSCs on both modified surfaces than polished Ti. Osteogenic matrix mineralisation assessed at 7 days post cell surface contact was the highest on the modSLA and then the SLA compared to polished $\mathrm{Ti}$ and tissue culture polystyrene (TCP). Collectively, this complex matrix of data sets suggests that SLA and modSLA distinguish between different subsets of cells within the heterogeneous population of MSCs based on physical adaptability to micro- and nanotopographic modifications of the Ti substrates. Yet the most intriguing is the inference deduced by correlating these results with pluripotency marker-related gene expression in proliferative and osteoinductive conditions as well as osteogenic mineralisation that permits us to hypothesise that micro- and nanotopographic modifications of the modSLA anomalously influence increased genetic plasticity of adherent MSCs in instigating a novel form of MSC dedifferentiation or stemness. 
TABLE 2: List of genetic markers and cumulative fold values of expression from three donors. Italicized values indicate the highest level of cumulative fold values of expression.

\begin{tabular}{|c|c|c|c|c|c|c|c|}
\hline Gene symbol & GM P & GM SLA & GM modSLA & OM P & OM SLA & OM modSLA & Category \\
\hline ACTB & 10.78 & 2.90 & 0.86 & 26.47 & 72.73 & 2.77 & Control \\
\hline RAF1 & 2.41 & 1.77 & 21.72 & 159.40 & 17.47 & 39.55 & Control \\
\hline CTNNB1 & 5.43 & 3.77 & 83.44 & 67.31 & 33.16 & 41.68 & Control \\
\hline GAPD & 2.43 & 2.98 & 6.70 & 1.40 & 6.34 & 174.07 & Control \\
\hline $18 \mathrm{~S}$ end control & 3.00 & 3.00 & 3.00 & 3.00 & 3.00 & 3.00 & Control \\
\hline Nanog & 6.81 & 2.62 & 21.92 & 4.29 & 15.56 & 3.91 & $\begin{array}{l}\text { Expression in undifferentiated cells/ } \\
\text { Maintenence of pluripotency }\end{array}$ \\
\hline POU5F1 & 6.61 & 6.42 & 259.53 & 235.38 & 48.55 & 8.81 & $\begin{array}{l}\text { Expression in undifferentiated cells/ } \\
\text { Maintenence of pluripotency }\end{array}$ \\
\hline DNMT3B & 5.09 & 4.24 & 116.44 & 26.11 & 23.51 & 38.12 & $\begin{array}{l}\text { Expression in undifferentiated cells/ } \\
\text { Maintenence of pluripotency }\end{array}$ \\
\hline GABRB3 & 5.77 & 5.31 & 189.67 & 222.74 & 10.99 & 126.86 & $\begin{array}{l}\text { Expression in undifferentiated cells/ } \\
\text { Maintenence of pluripotency }\end{array}$ \\
\hline BRIX & 4.79 & 1.50 & 3.88 & 3.03 & 6.01 & 51.52 & Correlation to stemness \\
\hline CD9 & 7.85 & 9.52 & 687.18 & 70.21 & 31.65 & 59.77 & Correlation to stemness \\
\hline COMMD3 & 3.95 & 3.89 & 97.32 & 140.21 & 32.07 & 103.13 & Correlation to stemness \\
\hline CRABP2 & 7.79 & 7.47 & 42.14 & 40.70 & 7.25 & 58.92 & Correlation to stemness \\
\hline FGF5 & 8.46 & 4.30 & 36.90 & 12.85 & 21.94 & 11.80 & Correlation to stemness \\
\hline GRB7 & 3.69 & 2.33 & 4.42 & 21.31 & 10.23 & 1.96 & Correlation to stemness \\
\hline IFITM1 & 11.03 & 17.96 & 485.02 & 5.04 & 14.71 & 100.14 & Correlation to stemness \\
\hline IFITM2 & 1.50 & 0.94 & 3.27 & 2.71 & 1.86 & 1.54 & Correlation to stemness \\
\hline IL6ST & 5.48 & 4.24 & 170.56 & 46.87 & 19.47 & 20.64 & Correlation to stemness \\
\hline IMP2 & 1.88 & 1.68 & 3.53 & 4.41 & 6.93 & 46.71 & Correlation to stemness \\
\hline KIT & 12.84 & 4.70 & 3.50 & 36.20 & 5.62 & 6.39 & Correlation to stemness \\
\hline LIFR & 2.51 & 0.00 & 18.35 & 401.85 & 97.84 & 36.63 & Correlation to stemness \\
\hline NOG & 0.87 & 0.42 & 10.06 & 19.35 & 3.53 & 4.46 & Correlation to stemness \\
\hline NR6A1 & 1.04 & 1.36 & 4.34 & 3.59 & 6.10 & 1.09 & Correlation to stemness \\
\hline PODXL & 3.77 & 2.41 & 91.91 & 22.15 & 7.08 & 9.14 & Correlation to stemness \\
\hline REST & 3.11 & 2.72 & 0.46 & 3.98 & 2.92 & 110.34 & Correlation to stemness \\
\hline SEMA3A & 2.75 & 2.17 & 38.41 & 33.00 & 2.55 & 0.30 & Correlation to stemness \\
\hline ACTC & 0.32 & 0.06 & 0.21 & 1.32 & 0.16 & 0.31 & Differentiation \\
\hline CGB & 4.15 & 1.68 & 10.72 & 25.19 & 5.75 & 15.10 & Differentiation \\
\hline COL1A1 & 5.82 & 4.23 & 112.68 & 16.47 & 12.34 & 10.92 & Differentiation \\
\hline DES & 5.58 & 6.73 & 3.49 & 24.31 & 42.50 & 25.70 & Differentiation \\
\hline FLT1 & 23.27 & 7.96 & 3.37 & 1.28 & 4.03 & 5.75 & Differentiation \\
\hline FN1 & 2.36 & 2.29 & 27.37 & 28.44 & 9.04 & 22.22 & Differentiation \\
\hline GATA6 & 3.40 & 2.63 & 10.14 & 5.28 & 2.28 & 4.11 & Differentiation \\
\hline GFAP & 1.96 & 2.20 & 1.33 & 0.39 & 0.33 & 0.00 & Differentiation \\
\hline LAMA1 & 1.97 & 1.03 & 32.05 & 133.14 & 20.26 & 72.38 & Differentiation \\
\hline LAMB1 & 3.96 & 3.11 & 28.62 & 230.22 & 35.29 & 233.72 & Differentiation \\
\hline LAMC1 & 3.45 & 2.28 & 31.04 & 43.53 & 9.32 & 17.86 & Differentiation \\
\hline NES & 3.00 & 1.45 & 14.82 & 24.33 & 3.67 & 6.19 & Differentiation \\
\hline PECAM1 & 18.22 & 19.32 & 1133.63 & 824.73 & 81.74 & 411.08 & Differentiation \\
\hline RUNX2 & 2.40 & 2.25 & 2.24 & 5.74 & 13.21 & 56.92 & Differentiation \\
\hline SERPINA1 & 20.17 & 20.92 & 67.17 & 11.01 & 22.72 & 5.60 & Differentiation \\
\hline SST & 0.08 & 0.98 & 7.81 & 1.82 & 0.00 & 0.00 & Differentiation \\
\hline SYP & 7.30 & 3.52 & 67.06 & 182.41 & 19.59 & 3.10 & Differentiation \\
\hline
\end{tabular}




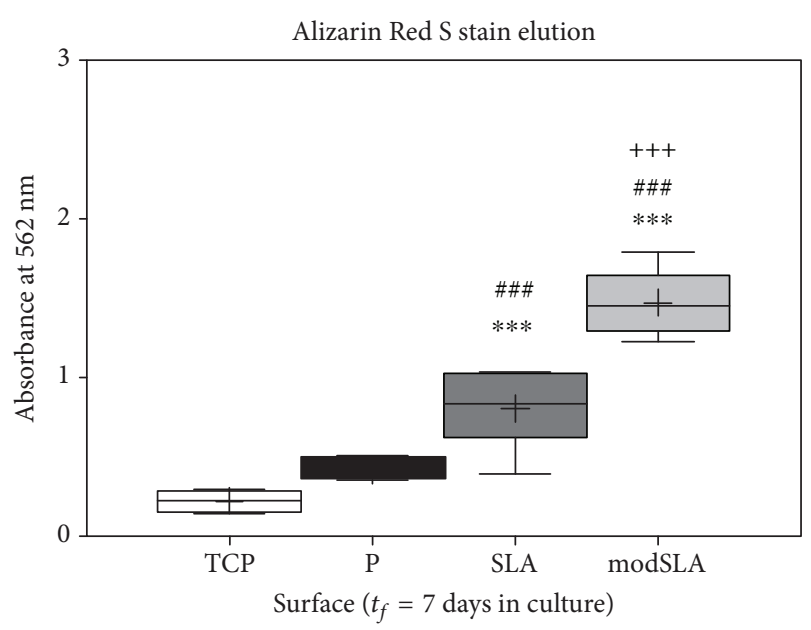

FIGURE 7: Assessment of osteogenic mineralisation with Alizarin Red S elution and spectrophotometry revealed rough Ti surfaces had induced significantly higher levels of calcium deposition by this time with the hydrophilic modSLA surface inducing significantly higher levels of calcium deposition than hydrophobic SLA. Box and whisker plot with minimum to maximum readings, $N=1 ; n=3$. ${ }^{* * *} p<0.001$, TCP vs. any Ti. ${ }^{\# \#} p<0.001, \mathrm{P}$ vs. rough. ${ }^{+++} p<0.001$, SLA vs. modSLA.

Although a set of criteria are routinely applied to defining MSC populations [21], these commonalities are not sufficient in deciphering intercellular variability within a population of MSCs or between populations isolated from different tissues or between different donors [35]. Moreover, the criteria of clonogenicity, expression of specific cell surface markers, and trilineage differentiation do not represent a population of homogeneous multipotent progenitors rather a population that contains multipotent progenitors indecipherable from nonmultipotent cells based on current standards [35]. The process of selection observed in this study seemingly pertains to an ability of SLA and modSLA to distinguish multipotent progenitors from nonmultipotent cells based on cytoskeletal plasticity. This infers the ability of a subpopulation of MSCs to adhere to the modified topography earlier due to a larger capacity of modulating the cytoskeletal apparatus in conjunction with the activity of cell surface adhesion molecules.

The variability of cell surface responses to the modified $\mathrm{Ti}$ biomaterials appears to depend more on cytoskeletal reorganisation than the activity of cell surface adhesion molecules as inferred from the constrained morphology of a lesser number of cells on the rough compared to their evenly concentric spread in higher numbers on the polished. This implies that while adhesion is initiated by cell surface molecules, MSC cytoskeletal plasticity determines the continuation of adhesion, rate of cellular spread, and morphologic adaptation to the topography. Within the context of this study, this distinguishing ability of the rough topographies appears to lead to progenitors with higher cytoskeletal plasticity to adhere successfully and result in higher subsequent osteogenic mineralisation. The results also present an additional aspect of MSCs with higher cytoskeletal plasticity per- tinent to genomic activity, which indicates that cells with higher cytoskeletal plasticity also have higher genomic plasticity compared to the heterogeneous population of MSCs adhering to polished $\mathrm{Ti}$, discussed later in this section. While the extent of influence of nanotopography of the hydrophilic modSLA compared to the hydrophobic SLA on cellular selectivity could not be clearly delineated by the experiments conducted in this study, it can be confidently stated that the higher cellular adhesion seen on the polished $\mathrm{Ti}$ results in equal chances of adherence for subpopulations of varying cytoskeletal plasticity, resulting in the significantly lesser osteogenic mineralisation compared to the microrough topographies.

The pluripotency marker gene expression arrays were complicated by patient-specific differences even though the three adult MSC populations similarly unexpressed genes relevant to embryonic or fetal development. However, differences in cumulative fold expression between cells on the SLA and modSLA suggest differences in the population of cells adherent to both rough topographies, which is particularly evident in proliferation inductive growth medium. The suppression of gene expression by the rough surfaces in osteogenic inductive medium indicates the overriding potential of osteogenic differentiation cues from the immediate microenvironment in addition to the lesser effective cues of the polished Ti surface in inducing osteogenesis. Whilst this observation does not address why both rough surfaces have similar numbers of adherent cells yet seemingly significant differences in pluripotency marker expression, it essentially suggests an induction of dedifferentiation of adherent MSCs on the modSLA, which is observably contrasted in proliferative conditions and concurrent with the extent of osteogenesis in inductive conditions. Furthermore, the inclusion of microRNA analyses for phenotypic markers might have revealed a tight regulation of translation of molecules crucial to each of the differentiation pathways. This is a novel find that may delineate nanotopography of the modSLA to variably affect fate determination by instigating novel cell signalling pathways pertinent to stemness despite both topographies similarly constraining cellular adhesion and morphological adaption and effecting osteogenic mineralisation.

The phenomenon of dedifferentiation has been reported in various instances in the scientific literature such as [36]. It is definable as a reversible shift in the phenotype of cells induced through changes in experimental conditions [36], or a result of the natural process of repair [37] or an intricate aspect of the characteristics of cancer cells during tumorigenesis [38]. Our proposition here differs from these and other reports by inferring a change in the state of stemness of cells from the phenotype of culture-expanded MSCs to an earlier progenitorial state through the effect of a particular Ti biomaterial surface modification. While it would have been highly informative to have evaluated adherent and nonadherent cells with the pluripotency gene expression miniarrays as well as additional assays that may have further explained these observations, the very frugal yet complex matrix of experimentation provided here adequately supports the basis of these results and their interpretation. It 
is extremely serendipitous that these results link adult stem cell heterogeneity and parameters associated with the phenotype of stemness.

In conclusion, the comparison of MSC adhesion and morphological adaptation to rough Ti surfaces correlated to stemness-related gene expression presented here indicates the importance of early phenotypic events in conditioning cells to an enhanced osteogenic phenotype as well as the significance of topographical cues on cellular selection and multipotential differentiation. These results present a basis for the heterogeneity of MSCs by indicating cytoskeletal adaptability an important determinant of stem cell "age," which seems to be directly related to genetic plasticity and is reversed by the micro- and nanostructured topography of the modSLA. Further elaboration of cellular and molecular processes underlying these cell-substrate interactions could improve implant surface characteristics to favourably adapt to weakened regenerative responses such as in the case of diabetes or age-related bone degenerative disorders. A consequence to this inference is that in addition to the current repertoire of cell surface markers used to immunophenotypically assess stem cell identity, as yet unidentified markers contributing to material-dependent fate determination of stem cells might further delineate cellular subsets within a heterogeneous MSC population.

\section{Conclusion}

This paper demonstrates that cytoskeletal plasticity is an intrinsic characteristic underlying the heterogeneity of a population of MSCs as shown by MSCs of a highly adaptable cytoskeleton overcoming the physical constraints of microstructure in adhering to rough topographic titanium biomaterials in the absence of deposited proteins or soluble factors. MSCs with higher cytoskeletal plasticity exhibit a higher level of genetic plasticity that is seemingly influenced by nanotopographic modifications in proliferative conditions and suppressed strongly by microtopographic modifications in osteoinductive conditions, thus underpinning the differential response of cells to the SLA and modSLA surfaces.

\section{Data Availability}

The datasets generated during and/or analysed during the current study are available from the corresponding author on reasonable request.

\section{Conflicts of Interest}

The authors declare that they have no conflicts of interest.

\section{Acknowledgments}

The authors extend their gratitude to the ITI Foundation for funding this research (grant code (491/2006)) and the University of London, Central Research Fund Grant, for funding the gene array experiments. The authors further extend their gratitude to the Institut Straumann AG Switzerland for providing the valuable titanium biomaterials. The authors also extend their gratitude to Dr. Shahzia Anjum from the UCL Institute of Child Health for her analysis of the gene expression miniarray-derived data. The authors also extend their gratitude to Prof. Tim Arnett from the University College London and Prof. Matt Dalby from the University of Glasgow for their review and insights towards the data presented in this paper. The publication of this article was self-funded by the authors.

\section{References}

[1] J. Uggeri, S. Guizzardi, R. Scandroglio, and R. Gatti, "Adhesion of human osteoblasts to titanium: a morpho-functional analysis with confocal microscopy," Micron, vol. 41, no. 3, pp. 210219, 2010.

[2] W. Att, N. Hori, M. Takeuchi et al., "Time-dependent degradation of titanium osteoconductivity: an implication of biological aging of implant materials," Biomaterials, vol. 30, no. 29, pp. 5352-5363, 2009.

[3] D. Buser, R. K. Schenk, S. Steinemann, J. P. Fiorellini, C. H. Fox, and H. Stich, "Influence of surface characteristics on bone integration of titanium implants. A histomorphometric study in miniature pigs," Journal of Biomedical Materials Research, vol. 25, no. 7, pp. 889-902, 1991.

[4] D. L. Cochran, P. V. Nummikoski, F. L. Higginbottom, J. S. Hermann, S. R. Makins, and D. Buser, "Evaluation of an endosseous titanium implant with a sandblasted and acidetched surface in the canine mandible: radiographic results," Clinical Oral Implants Research, vol. 7, no. 3, pp. 240-252, 1996.

[5] D. Buser, T. Nydegger, H. Hirt, D. Cochran, and L. Nolte, "Removal torque values of titanium implants in the maxilla of miniature pigs," International Journal of Oral \& Maxillofacial Implants, vol. 13, pp. 611-619, 1998.

[6] D. Buser, T. Nydegger, T. Oxland et al., "Interface shear strength of titanium implants with a sandblasted and acidetched surface: a biomechanical study in the maxilla of miniature pigs," Journal of Biomedical Materials Research, vol. 45, no. 2, pp. 75-83, 1999.

[7] M. Bornstein, A. Lussi, B. Schmid, U. Belser, and D. Buser, "Early loading of nonsubmerged titanium implants with a sandblasted and acid-etched (SLA) surface: 3-year results of a prospective study in partially edentulous patients," The International Journal of Oral \& Maxillofacial Implants, vol. 18, pp. 659-666, 2003.

[8] F. J. J. van Velzen, R. Ofec, E. A. J. M. Schulten, and C. M. ten Bruggenkate, "10-year survival rate and the incidence of periimplant disease of 374 titanium dental implants with a SLA surface: a prospective cohort study in 177 fully and partially edentulous patients," Clinical Oral Implants Research, vol. 26, no. 10, pp. 1121-1128, 2015.

[9] A. Wennerberg and T. Albrektsson, "Effects of titanium surface topography on bone integration: a systematic review," Clinical Oral Implants Research, vol. 20, pp. 172184, 2009.

[10] D. Buser, N. Broggini, M. Wieland et al., "Enhanced bone apposition to a chemically modified SLA titanium surface," Journal of Dental Research, vol. 83, no. 7, pp. 529-533, 2004.

[11] M. M. Bornstein, J. G. Wittneben, U. Brägger, and D. Buser, "Early loading at 21 days of non-submerged titanium implants with a chemically modified sandblasted and acid-etched 
surface: 3-year results of a prospective study in the posterior mandible," Journal of Periodontology, vol. 81, no. 6, pp. 809$818,2010$.

[12] F. Schwarz, M. Wieland, Z. Schwartz et al., "Potential of chemically modified hydrophilic surface characteristics to support tissue integration of titanium dental implants," Journal of Biomedical Materials Research Part B: Applied Biomaterials, vol. 88B, no. 2, pp. 544-557, 2009.

[13] J. Alayan, C. Vaquette, S. Saifzadeh, D. Hutmacher, and S. Ivanovski, "Comparison of early osseointegration of SLA ${ }^{\circledR}$ and SLActive ${ }^{\circledR}$ implants in maxillary sinus augmentation: a pilot study," Clinical Oral Implants Research, vol. 28, no. 11, pp. 1325-1333, 2017.

[14] N. Donos, S. Hamlet, N. P. Lang et al., "Gene expression profile of osseointegration of a hydrophilic compared with a hydrophobic microrough implant surface," Clinical Oral Implants Research, vol. 22, no. 4, pp. 365-372, 2011.

[15] S. Ivanovski, S. Hamlet, G. E. Salvi et al., "Transcriptional profiling of osseointegration in humans," Clinical Oral Implants Research, vol. 22, no. 4, pp. 373-381, 2011.

[16] E. Calciolari, N. Mardas, X. Dereka, A. K. Anagnostopoulos, G. T. Tsangaris, and N. Donos, "Protein expression during early stages of bone regeneration under hydrophobic and hydrophilic titanium domes. A pilot study," J Periodontal Res, vol. 53, no. 2, pp. 174-187, 2018.

[17] N. P. Lang, G. E. Salvi, G. Huynh-Ba, S. Ivanovski, N. Donos, and D. D. Bosshardt, "Early osseointegration to hydrophilic and hydrophobic implant surfaces in humans," Clinical Oral Implants Research, vol. 22, no. 4, pp. 349-356, 2011.

[18] P. M. Brett, J. Harle, V. Salih et al., "Roughness response genes in osteoblasts," Bone, vol. 35, no. 1, pp. 124-133, 2004.

[19] G. Zhao, Z. Schwartz, M. Wieland et al., "High surface energy enhances cell response to titanium substrate microstructure," Journal of Biomedical Materials Research Part A, vol. 74A, no. 1, pp. 49-58, 2005.

[20] I. Wall, N. Donos, K. Carlqvist, F. Jones, and P. Brett, "Modified titanium surfaces promote accelerated osteogenic differentiation of mesenchymal stromal cells in vitro," Bone, vol. 45, no. 1, pp. 17-26, 2009.

[21] M. Dominici, K. le Blanc, I. Mueller et al., "Minimal criteria for defining multipotent mesenchymal stromal cells. The International Society for Cellular Therapy position statement," Cytotherapy, vol. 8, no. 4, pp. 315-317, 2006.

[22] M. R. Khan, N. Donos, V. Salih, and P. M. Brett, "The enhanced modulation of key bone matrix components by modified titanium implant surfaces," Bone, vol. 50, no. 1, pp. 1-8, 2012.

[23] M. Khan, N. Donos, V. Salih, and P. Brett, "Receptor kinase AXL is modulated in the osteogenic differentiation of human mesenchymal stromal cells on modified titanium implant surfaces," Journal of Stem Cell Research \& Therapy, vol. 4, no. 9, 2014.

[24] C. Huang, J. Dai, and X. A. Zhang, "Environmental physical cues determine the lineage specification of mesenchymal stem cells," Biochimica et Biophysica Acta (BBA) - General Subjects, vol. 1850, no. 6, pp. 1261-1266, 2015.

[25] R. J. Miron, C. J. Oates, A. Molenberg, M. Dard, and D. W. Hamilton, "The effect of enamel matrix proteins on the spreading, proliferation and differentiation of osteoblasts cultured on titanium surfaces," Biomaterials, vol. 31, no. 3, pp. 449-460, 2010.
[26] H. C. Lai, L. F. Zhuang, X. Liu, M. Wieland, Z. Y. Zhang, and Z. Y. Zhang, "The influence of surface energy on early adherent events of osteoblast on titanium substrates," Journal of Biomedical Materials Research Part A, vol. 93A, no. 1, pp. 289-296, 2010.

[27] Z. Qu, X. Rausch-Fan, M. Wieland, M. Matejka, and A. Schedle, "The initial attachment and subsequent behavior regulation of osteoblasts by dental implant surface modification," Journal of Biomedical Materials Research Part A, vol. 82A, no. 3, pp. 658-668, 2007.

[28] G. Zhao, A. Raines, M. Wieland, Z. Schwartz, and B. Boyan, "Requirement for both micron- and submicron scale structure for synergistic responses of osteoblasts to substrate surface energy and topography," Biomaterials, vol. 28, no. 18, pp. 2821-2829, 2007.

[29] C. Galli, M. Piemontese, S. Lumetti, F. Ravanetti, G. M. Macaluso, and G. Passeri, "Actin cytoskeleton controls activation of $\mathrm{Wnt} / \beta$-catenin signaling in mesenchymal cells on implant surfaces with different topographies," Acta Biomaterialia, vol. 8, no. 8, pp. 2963-2968, 2012.

[30] P. D. H. Prowse, C. G. Elliott, J. Hutter, and D. W. Hamilton, "Inhibition of Rac and ROCK signalling influence osteoblast adhesion, differentiation and mineralization on titanium topographies," PLoS One, vol. 8, no. 3, article e58898, 2013.

[31] S. Lumetti, S. Mazzotta, S. Ferrillo et al., "RhoA controls Wnt upregulation on microstructured titanium surfaces," BioMed Research International, vol. 2014, Article ID 401859, 9 pages, 2014.

[32] P. Lagonegro, G. Trevisi, L. Nasi et al., "Osteoblasts preferentially adhere to peaks on micro-structured titanium," Dental Materials Journal, vol. 37, no. 2, pp. 278-285, 2018.

[33] I. Sekiya, B. L. Larson, J. R. Smith, R. Pochampally, J.\&;. G. Cui, and D. J. Prockop, "Expansion of human adult stem cells from bone marrow stroma: conditions that maximize the yields of early progenitors and evaluate their quality," Stem Cells, vol. 20 , no. 6 , pp. $530-541,2002$.

[34] F. Rupp, L. Scheideler, N. Olshanska, M. de Wild, M. Wieland, and J. Geis-Gerstorfer, "Enhancing surface free energy and hydrophilicity through chemical modification of microstructured titanium implant surfaces," Journal of Biomedical Materials Research Part A, vol. 76A, no. 2, pp. 323-334, 2006.

[35] C. McLeod and R. Mauck, "On the origin and impact of mesenchymal stem cell heterogeneity: new insights and emerging tools for single cell analysis," European Cells and Materials, vol. 34, pp. 217-231, 2017.

[36] L. Song, N. E. Webb, Y. Song, and R. S. Tuan, "Identification and functional analysis of candidate genes regulating mesenchymal stem cell self-renewal and multipotency," Stem Cells, vol. 24, no. 7, pp. 1707-1718, 2006.

[37] R. Londono, W. Wenzhong, B. Wang, R. S. Tuan, and T. P. Lozito, "Cartilage and muscle cell fate and origins during lizard tail regeneration," Frontiers in Bioengineering and Biotechnology, vol. 5, p. 70, 2017.

[38] L. Di, L.-J. Liu, Y.-M. Yan et al., "Discovery of a natural smallmolecule compound that suppresses tumor EMT, stemness and metastasis by inhibiting TGF $\beta / \mathrm{BMP}$ signaling in triplenegative breast cancer," Journal of Experimental \& Clinical Cancer Research, vol. 38, no. 1, p. 134, 2019. 


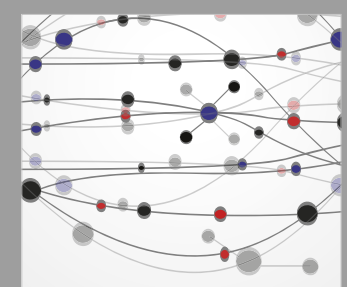

The Scientific World Journal
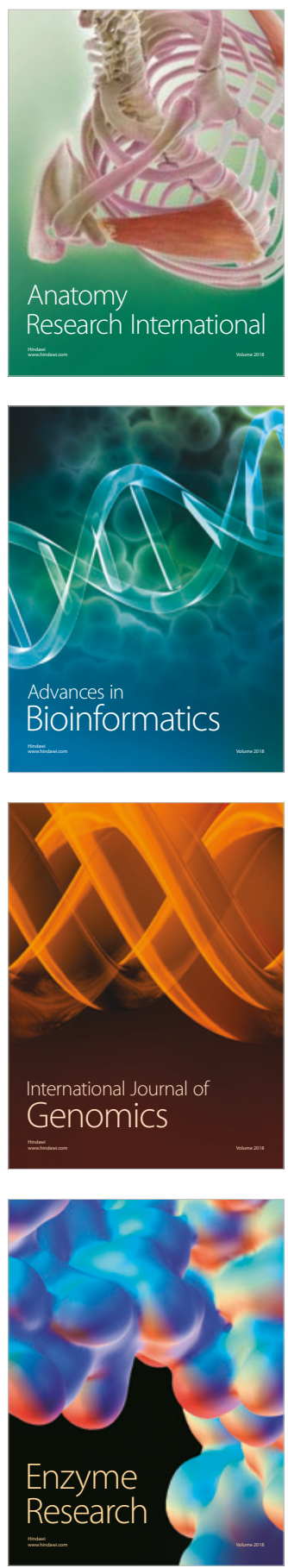
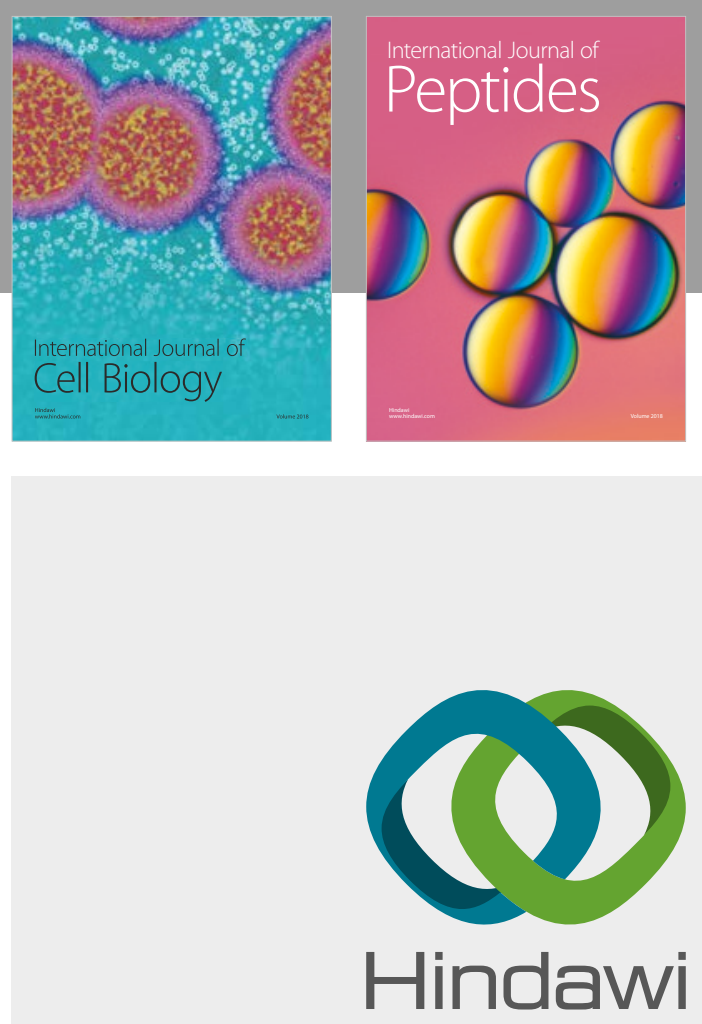

Submit your manuscripts at

www.hindawi.com
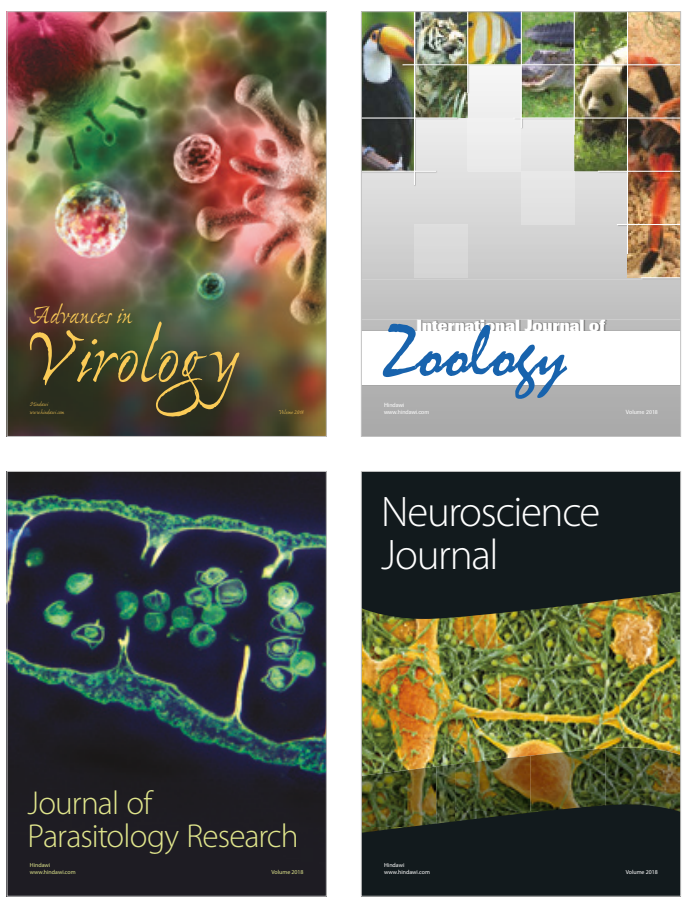
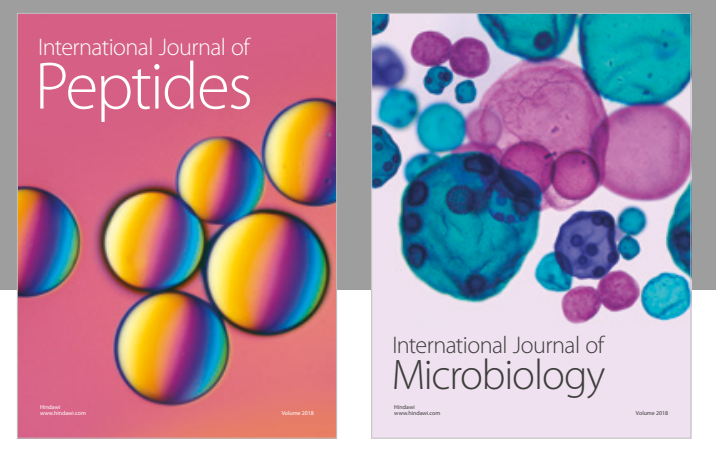

nternational Journal of Microbiology
Journal of
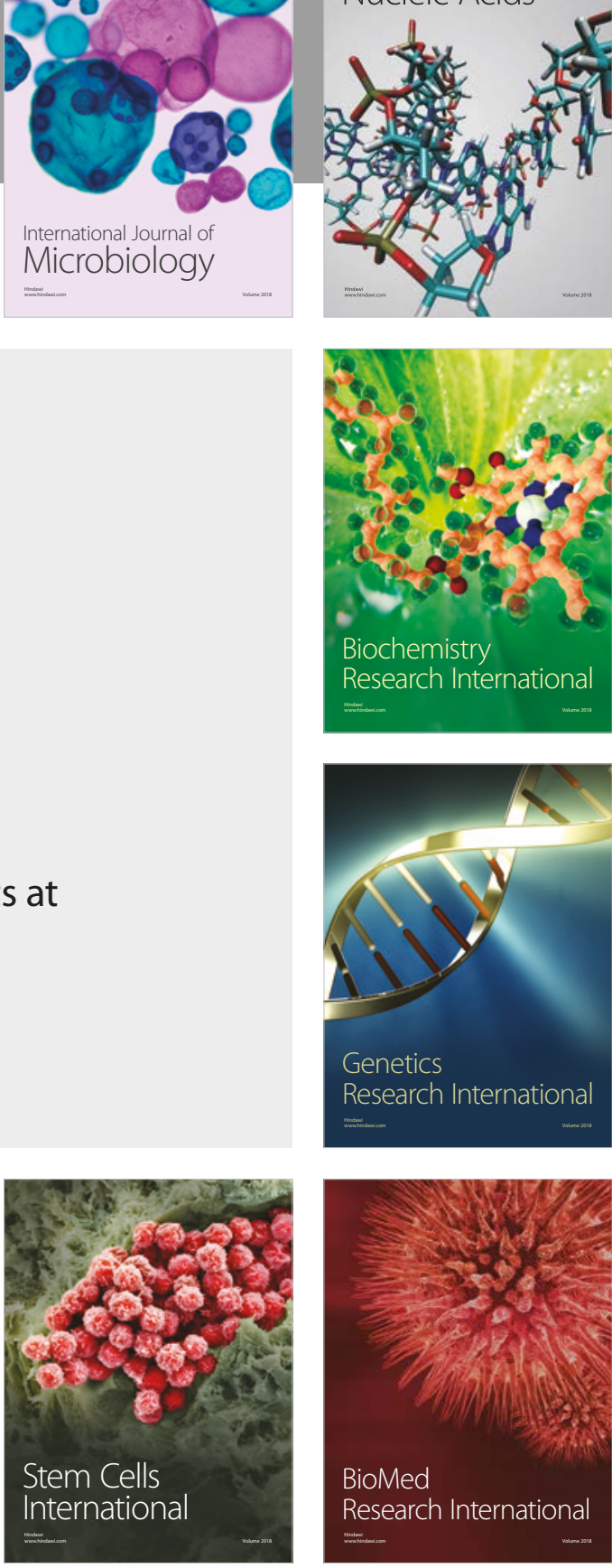
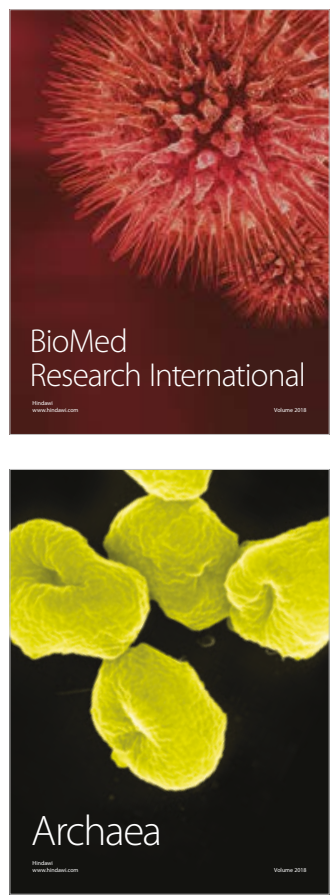